June 2001 • NREL/TP-500-29494

\title{
NREL Unsteady Aerodynamics Experiment in the NASA-Ames Wind Tunnel: A Comparison of Predictions to Measurements
}

D. Simms

S. Schreck

M. Hand

L.J. Fingersh

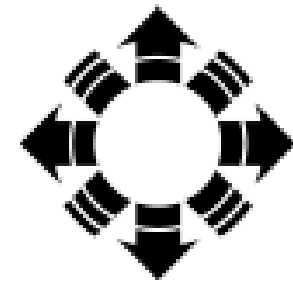

National Renewable Energy Laboratory

1617 Cole Boulevard

Golden, Colorado 80401-3393

NREL is a U.S. Department of Energy Laboratory

Operated by Midwest Research Institute $\bullet$ Battelle $\bullet$ Bechtel

Contract No. DE-AC36-99-G010337 


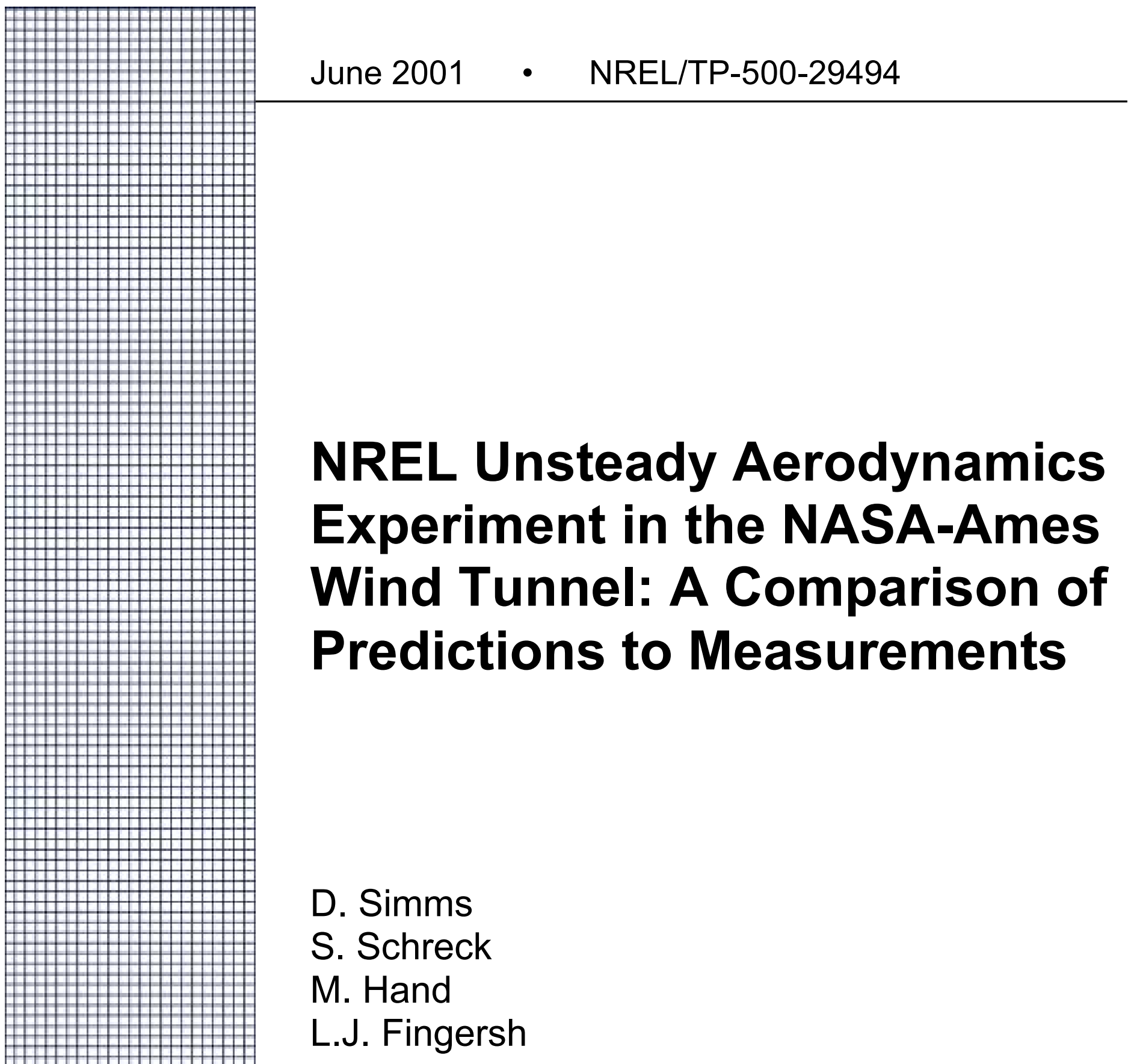

Prepared under Task No. WER1.1110

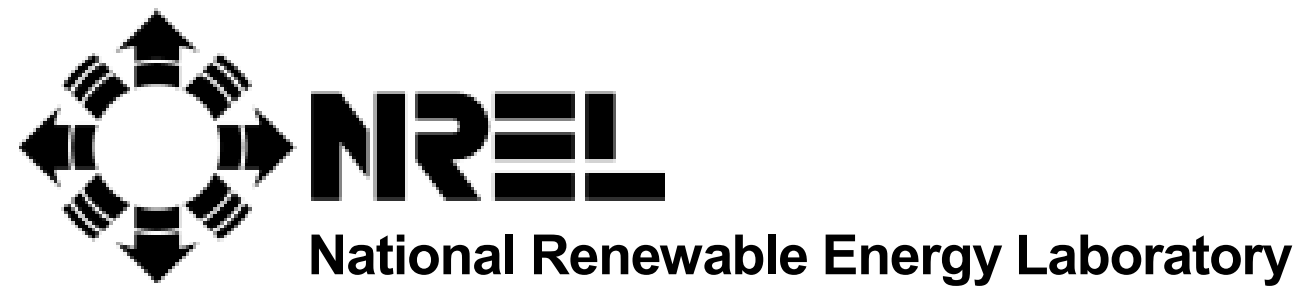

1617 Cole Boulevard

Golden, Colorado 80401-3393

NREL is a U.S. Department of Energy Laboratory

Operated by Midwest Research Institute $\bullet$ Battelle $\bullet$ Bechtel

Contract No. DE-AC36-99-G010337 


\section{NOTICE}

This report was prepared as an account of work sponsored by an agency of the United States government. Neither the United States government nor any agency thereof, nor any of their employees, makes any warranty, express or implied, or assumes any legal liability or responsibility for the accuracy, completeness, or usefulness of any information, apparatus, product, or process disclosed, or represents that its use would not infringe privately owned rights. Reference herein to any specific commercial product, process, or service by trade name, trademark, manufacturer, or otherwise does not necessarily constitute or imply its endorsement, recommendation, or favoring by the United States government or any agency thereof. The views and opinions of authors expressed herein do not necessarily state or reflect those of the United States government or any agency thereof.

Available electronically at http://www.doe.gov/bridge

Available for a processing fee to U.S. Department of Energy

and its contractors, in paper, from:

U.S. Department of Energy

Office of Scientific and Technical Information

P.O. Box 62

Oak Ridge, TN 37831-0062

phone: 865.576.8401

fax: 865.576.5728

email: reports@adonis.osti.gov

Available for sale to the public, in paper, from:

U.S. Department of Commerce

National Technical Information Service

5285 Port Royal Road

Springfield, VA 22161

phone: 800.553.6847

fax: 703.605.6900

email: orders@ntis.fedworld.gov

online ordering: http://www.ntis.gov/ordering.htm

Printed on paper containing at least $50 \%$ wastepaper, including $20 \%$ postconsumer waste 


\section{Table of Contents}

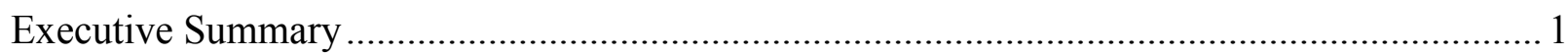

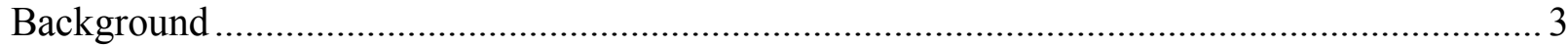

Wind Tunnel Test Objectives and Resulting Data...................................................... 4

Examples of Data Quality and Reliability ........................................................... 6

Blind Comparison Objectives and Background................................................... 12

Summary of Blind-Comparison Results ........................................................... 15

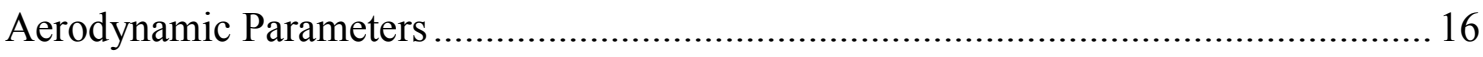

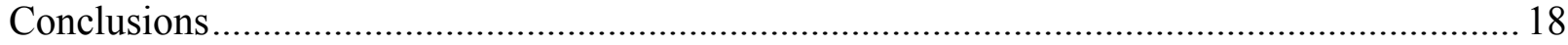

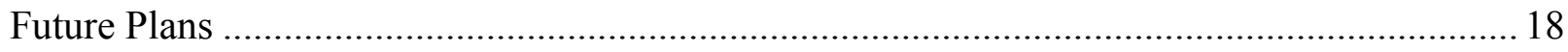

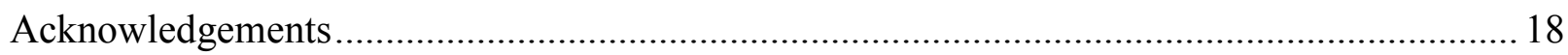

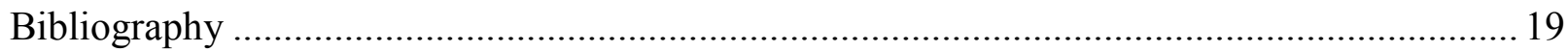

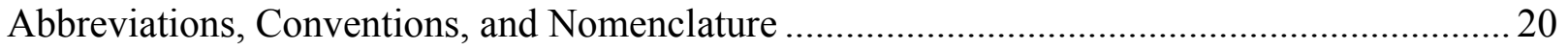




\section{List of Figures}

Figure 1. Representative test section speed records for nominal speeds of 5, 10, 15, 20, and $25 \mathrm{~m} / \mathrm{s}$.

Standard deviations in speed are annotated for each record.

Figure 2. Blockage estimate for the UAE in the NASA-Ames 24.4-m (80') by 36.6-m (120') wind tunnel. Results are shown for blade pitch angles of 0,3 , and $6^{\circ}$. 6

Figure 3. Representative angle of attack data from 36 consecutive blade rotation cycles, for all five span stations. Test section wind speed $=13 \mathrm{~m} / \mathrm{s}$, yaw angle $=30^{\circ}$. .7

Figure 4. $C_{n}, C_{t}$, and $C_{m}$ records as a function of angle of attack for 36 consecutive blade rotation cycles at $0.30 \mathrm{R}$. Test section wind speed $=13 \mathrm{~m} / \mathrm{s}$, yaw angle $=30^{\circ}$...... 8

Figure 5. Instantaneous $c_{p}$ distributions from $0.47 \mathrm{R}$, for 36 consecutive blade rotation cycles. Top panel: azimuth angle $=0^{\circ}$. Bottom panel: azimuth angle $=180^{\circ}$. Test section wind speed $=13 \mathrm{~m} / \mathrm{s}$, yaw angle $=30^{\circ}$. .9

Figure 6. Each panel contains 36 cycles of surface pressure data from two different data sets. Data sets in top panel were acquired 21 minutes apart; data sets in bottom panel were taken one week apart. (Tap locations relative to $\mathrm{x} / \mathrm{c}$ axis in both plots were shifted slightly for display clarity.) Test section speed $=9 \mathrm{~m} / \mathrm{s}$, yaw angle $=0^{\circ}, 0.47 \mathrm{R}$ .11

Figure 7. Comparison between test section total pressure data acquired via UAE instrumentation

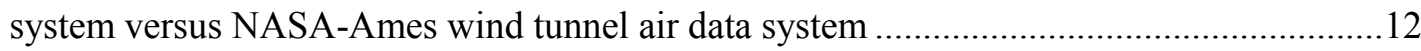

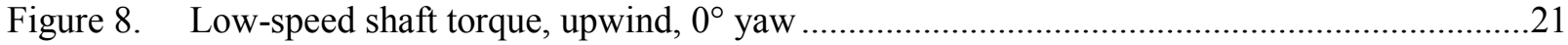

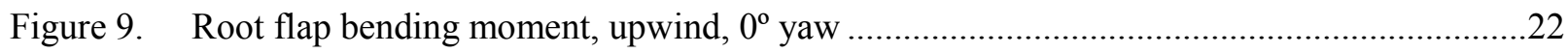

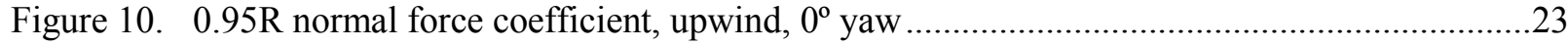

Figure 11. 0.95R tangent force coefficient, upwind, $0^{\circ}$ yaw ..........................................................24

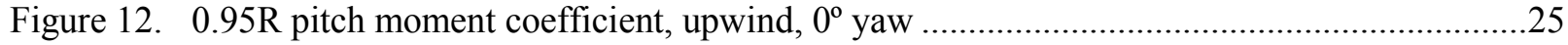

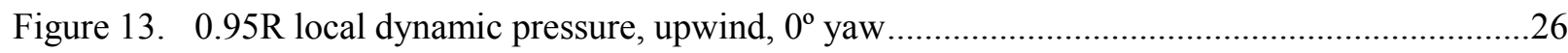

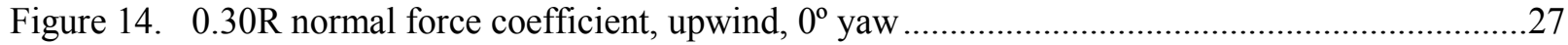

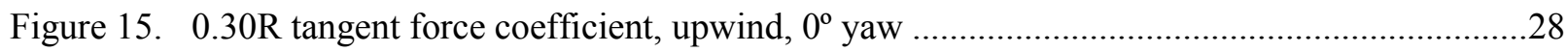

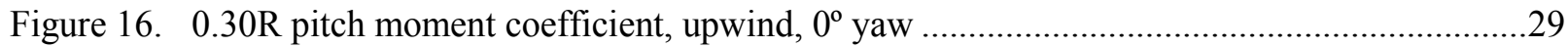

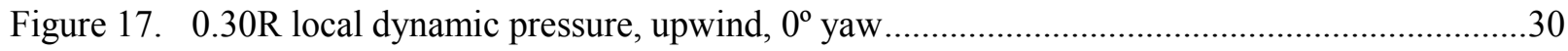

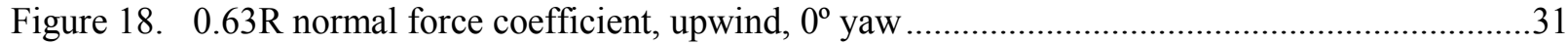

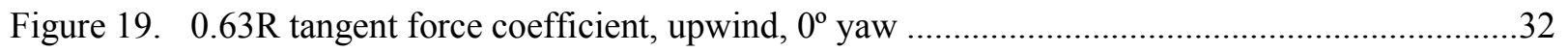

Figure 20. $0.63 \mathrm{R}$ pitch moment force coefficient, upwind, $0^{\circ}$ yaw ……............................................33

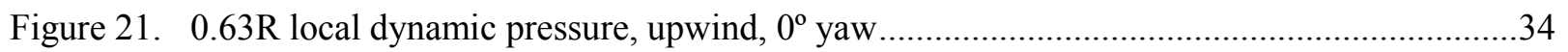

Figure 22. $\quad 0.30 \mathrm{R}, 15 \mathrm{~m} / \mathrm{s}$ wind speed, $30^{\circ}$ yaw, aeroelastic codes .................................................35

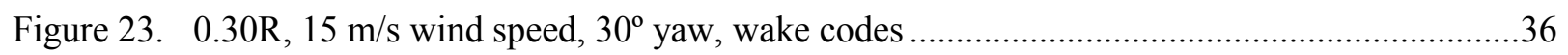

Figure 24. $0.30 \mathrm{R}, 15 \mathrm{~m} / \mathrm{s}$ wind speed, $60^{\circ}$ yaw, aeroelastic codes (Boom wake interference from $60^{\circ}-125^{\circ}$ azimuth)

Figure 25. $0.30 \mathrm{R}, 15 \mathrm{~m} / \mathrm{s}$ wind speed, $60^{\circ}$ yaw, wake codes. (Boom wake interference from $60^{\circ}-125^{\circ}$ azimuth). .38

Figure 26. $0.47 \mathrm{R}, 15 \mathrm{~m} / \mathrm{s}$ wind speed, $30^{\circ}$ yaw, aeroelastic codes 39 
Figure 27. $0.47 \mathrm{R}, 15 \mathrm{~m} / \mathrm{s}$ wind speed, $30^{\circ}$ yaw, wake codes

Figure 28. $0.47 \mathrm{R}, 15 \mathrm{~m} / \mathrm{s}$ wind speed, $60^{\circ}$ yaw, aeroelastic codes (Boom wake interference from $70^{\circ}-100^{\circ}$ azimuth

Figure 29. $0.47 \mathrm{R}, 15 \mathrm{~m} / \mathrm{s}$ wind speed, $60^{\circ}$ yaw, wake codes (Boom wake interference from $70^{\circ}-100^{\circ}$ azimuth .42

Figure 30. Tower shadow at $0.47 \mathrm{R}, 7 \mathrm{~m} / \mathrm{s}$ wind speed, aeroelastic and wake codes .43

Figure 31. Tower shadow at $0.47 \mathrm{R}, 17 \mathrm{~m} / \mathrm{s}$ wind speed (upwind, zero yaw actually $15 \mathrm{~m} / \mathrm{s}$ ) aeroelastic and wake codes 


\section{Executive Summary}

Evidently, we're not as smart as we would like to think we are, especially in predicting wind turbine behavior. We're learning that the physics of wind turbines are much more complex than we had imagined, especially the underlying aerodynamic responses. Experts rely heavily on computer modeling tools to handle the complex physical interactions that are essential to accurate quantification of turbine performance and component loads. In this report, we describe a collaborative international effort to compare wind turbine model predictions with measured behavior. However, based on the results described herein, there is obvious need for additional work.

Currently, wind turbine designers rely on safety factors to compensate for the effects of unknown loads acting on the turbine structure. This results in components that are overdesigned because precise load levels and load paths are unknown. In order to advance wind turbine technology, the forces acting on the turbine structure must be accurately characterized, because these forces translate directly into loads imparted to the wind turbine structure and resulting power production. Once these forces are more accurately characterized, we will better understand load paths and can therefore optimize turbine structures.

To address this problem, the National Renewable Energy Laboratory (NREL) conducted the Unsteady Aerodynamics Experiment (UAE), which was a test of an extensively instrumented wind turbine in the giant NASA-Ames 24.4-m (80') by 36.6-m (120') wind tunnel. To maximize the benefits from testing, NREL formed a Science Panel of advisers comprised of wind turbine aerodynamics and modeling experts throughout the world. NREL used the Science Panel's guidance to specify the conditions and configurations under which the turbine was operated in the wind tunnel. The panel also helped define test priorities and objectives that would be effective for wind turbine modeling tool development and validation.

The NREL/ NASA-Ames wind tunnel testing was completed in May 2000 and was very successful in that almost all data specified by the Science Panel were obtained. Data sets were acquired from a total of more than 1,700 different turbine test conditions. Testing yielded exceptional data accuracy and reliability in the absence of experimental artifacts. These data are a valuable resource for developing and validating wind turbine aerodynamics codes.

Immediately following the wind tunnel test, NREL organized a "blind comparison" in which wind turbine modeling experts were invited to predict the behavior of the NREL wind turbine operating under precisely controlled conditions in the wind tunnel. This was a significant collaborative effort on the part of the international wind turbine research community. Thirty experts from 18 organizations (12 European) participated in the blind comparison. Work by these individuals resulted in models generated using a total of 19 different wind turbine modeling tools.

Wind tunnel experiment data were not revealed prior to the blind comparison. In order to participate in the collaboration, the experts ran their models to predict loads and performance at selected wind velocities and yaw angles, in both upwind and downwind configurations (a total of 20 different cases). Cases specified corresponded to selected conditions run during the NREL/ NASA-Ames wind tunnel test. The selected cases represented a small subset $(<1 \%)$ of all data obtained during the test. Participants submitted their results to NREL. A meeting was held during which resulting predictions were presented and compared with measured wind tunnel data.

The blind comparison study was implemented in a way to identify uncertainties associated with wind turbine model predictions that included the effects of both the modeling tool and modeler. Prediction uncertainties can be attributed to many sources within the modeling tool, including the aerodynamics 
algorithms and modeling methodologies employed. Prediction uncertainties can also originate from a wide variety of assumptions and decisions made by the modeler. All modelers were provided with the exact same detailed UAE turbine description, but the development of model inputs is a highly selective process that relies heavily on modeler experience and intuition. Modeler selection of input parameters can dramatically affect resulting predictions. For example, one major area of subjectivity involved modeler selection of blade airfoil performance characteristics. The turbine description database included results of many 2-D wind tunnel tests of the S809 airfoils used on the blades. It was left to the modeler to ascertain which of these datasets (or which combination of them) to utilize. Also, many models require modification of the 2-D airfoil performance data to account for rotational and 3-D effects. These modifications were also left to the discretion of the modeler. The airfoil selection and modification decisions are typical for a wind turbine modeler, and it was the intent of NREL to include the associated resulting uncertainties in the blind comparison results.

The amount of information about the UAE turbine configuration provided to the modelers is probably similar to that of a typical operating industry turbine. It is significantly more information than a modeler would have of a proposed prototype turbine. In this report, we do not go into specific reasons identifying how model input selections and code differences explain discrepancies in resulting code predictions. The reasons are complex and will have to be explored further in follow-up research. This report shows the scatter and variations among the various predictions, and highlights general trends in differences between the code predictions and test results.

Blind comparison results were not favorable. Modelers were surprised by the wide variations evident between their various code predictions. There were also significant deviations from measured wind tunnel results. More disconcerting was the scatter evident under supposedly easy-to-predict typical turbine operating conditions. For example, under no-yaw, steady-state, no-stall conditions, turbine power predictions ranged from $25 \%$ to $175 \%$ of measured, and blade bending-force predictions ranged from $85 \%$ to $150 \%$ of measured. Results at higher wind speeds in stall were especially disappointing - power predictions ranged from $30 \%$ to $275 \%$ of measured, and blade-bending predictions ranged from $60 \%$ to $125 \%$ of measured.

Therefore, to attack this problem, aggressive, targeted exploitation of the NREL/NASA-Ames UAE database, beyond that documented herein, is needed. Work will be undertaken to support advances along three principal pathways. In the near term, disciplined used of the wind tunnel data will allow existing turbine models to be better tuned, thus enhancing model accuracy for restricted sets of configurations and conditions. Over the longer term, these data will enable construction and validation of more accurate, though still efficient and reliable, classes of models that are more firmly anchored in flow physics and less dependent upon empiricism. To support long-term and continued advances in modeling, the wind tunnel database must be systematically and rationally scrutinized to disclose flow structures and interactions currently unrecognized or poorly understood. Finally, penetrating physical inquiry, formalization of understanding in models, and rigorous validation will undoubtedly guide the direction of future experimentation and research.

As researchers and model users devoted to developing aerodynamics algorithms used in these wind turbine modeling tools, we tend to be unduly optimistic about the advances - especially when compared to the relatively crude capabilities available only 10 or so years ago. But we should not sell ourselves short in thinking we have solved all the problems. On the contrary, the blind comparison results described in this report indicate that we still have quite a bit of work ahead of us. 


\section{Background}

Over the last decade, the wind turbine research community has made significant improvement in the ability to simulate wind turbine performance and loads. These improvements have been passed to the wind industry in the form of newer, more sophisticated modeling tools. Modeling experts have applied these new tools to successfully advance the state of wind turbine technology and lower the cost of windgenerated energy.

Ongoing advances in computer technology have provided the means to evolve wind turbine modeling tools to increasing levels of detail and complexity. It has reached the point where proper application of these tools is highly dependent on use by knowledgeable individuals. These modeling experts have spent many years developing specialized skills in conjunction with modeling tool improvements. However, there are also certain deficiencies associated with the use of these modeling tools. Modeling experts are generally aware of these deficiencies, and tend to limit or avoid simulation of turbine operation in the associated problem areas. These include operation under more severe conditions of gusts, direction changes, yaw, shear, and tower shadow. These limitations are unfortunate in that it is often important to simulate operation under such conditions to be able to estimate extreme loads needed to design turbines for successful long-term operation. Exact quantification of the limitations are not well defined and depend significantly on modeler skill and experience to compensate for modeling tool inadequacies.

In order to address these problems, NREL planned and conducted a comprehensive test program called the Unsteady Aerodynamics Experiment (UAE). [1] For this experiment, NREL built an extensively instrumented, 10-m-diameter horizontal-axis research wind turbine. It has been field-tested under typical outdoor conditions for more than 10 years at the National Wind Technology Center (NWTC). [2] Much work has gone into developing and perfecting instrumentation systems needed to directly measure and characterize the aerodynamic forces acting on the rotating wind turbine blade.

UAE field testing showed that the typical outdoor conditions under which a wind turbine operates are incredibly complex. Quickly-changing wind velocity, rapidly-shifting wind directions, and widelyvarying levels of turbulence and shear are contributing factors. There is no such thing as steady-state in the field. Observed variations in resulting aerodynamic responses were equally complex. In addition to the work undertaken by NREL on the UAE, many years of similar testing and analyses done by the international wind energy research community [3] produced corroborating results. All of these experiments revealed that the underlying flow physics of wind turbine aerodynamic responses tended to be much more complex than originally assumed. This led to the recognition that a major factor contributing to modeling tool limitations was due to inadequacies in the aerodynamics algorithms within the tools themselves. Europe has funded research teams of aerodynamics experts from many European Union countries (Joule projects) to address the problem. [4]. European and U.S. researchers reached the same conclusion - it was deemed necessary to operate a full-scale turbine under precisely controlled conditions in order to be able to successfully associate complex aerodynamic phenomena with specific inflow and operating conditions. Both the United States and Europe therefore began to independently plan comprehensive wind tunnel tests designed to characterize wind turbine aerodynamic responses.

In the United States, this led to the culmination of the UAE, which was to test the NREL wind turbine in the giant NASA-Ames 24.4-m (80') by 36.6-m (120') wind tunnel. To maximize test benefits, NREL formed a Science Panel of advisers comprised of wind turbine aerodynamics and modeling experts throughout the world. With the panel's guidance, NREL was able to specify the conditions and configurations under which the turbine was operated in the wind tunnel. This panel was initially convened in October 1998 to provide guidance in defining test priorities and objectives that would be effective for wind turbine modeling tool development and validation. [5] The NREL/NASA-Ames wind tunnel testing was completed in May 2000 and was very successful in that almost all data specified by the 
Science Panel were obtained. [6] Data sets were acquired from a total of more than 1700 different turbine test conditions.

In this report, we review the NREL/NASA-Ames wind tunnel test objectives, look at the wind tunnel test data quality, and describe a collaborative effort on the part of the international wind turbine research community in which resulting test data are used to better understand the deficiencies in wind turbine modeling tools. Following the wind tunnel test, a "blind comparison" was immediately undertaken in which wind turbine modeling experts were invited to predict the behavior of the NREL wind turbine operating under precisely controlled conditions in the wind tunnel. Wind tunnel experiment data were not revealed prior to the blind comparison. In order to participate in the collaboration, the experts were asked to generate models of the NREL turbine using their favorite modeling tools. They then ran the models to predict loads and performance at selected wind velocities and yaw angles, in both upwind and downwind configurations (a total of 20 different cases). Cases specified corresponded to selected conditions run during the NREL/ NASA-Ames wind tunnel test. The selected cases represented a small subset $(<1 \%)$ of all data obtained during the test.

Results of the blind comparison were presented at the $2^{\text {nd }}$ NREL/NASA-Ames Science Panel meeting held at the NWTC on December 5 and 6, 2000. The blind comparison was the first step in using wind tunnel test data to evaluate the aerodynamics algorithms used in wind turbine modeling tools. Thirty experts from 18 organizations (12 European) participated in the blind comparison. Work by these individuals resulted in models generated using a total of 19 different wind turbine modeling tools. A list of the participants and modeling tools used is shown in Table 1. They represent an international assortment of industry, academic, and government organizations specializing in wind turbine performance and loads modeling. NREL began the meeting by summarizing activities leading up to the wind tunnel test, including installation of the turbine at the NASA-Ames facility. NREL then presented selected data resulting from the test to give the attendees an idea of the quality and uncertainty associated with the measured data. Specific cases of participants' results plotted against corresponding wind tunnel test data were then shown. Because the objective of the test and meeting was to address wind turbine aerodynamics, most of the plots targeted specific aerodynamic phenomena.

\section{Wind Tunnel Test Objectives and Resulting Data}

The NREL/ NASA-Ames wind tunnel test was designed to provide accurate and reliable experimental measurements, having high spatial and temporal resolution, for a realistic rotating blade geometry, under closely matched conditions of dynamic similarity, and in the presence of strictly controlled inflow conditions. These demanding objectives were met by testing the NREL UAE in the NASA-Ames 24.4-m $\left(80^{\prime}\right)$ by $36.6-\mathrm{m}\left(120^{\prime}\right)$ wind tunnel. In this section, we document the accuracy and reliability of these data, as well as some attributes of the UAE instrumentation system and wind tunnel that impacted accuracy and reliability.

The NASA-Ames Research Center's National Full-Scale Aerodynamics Complex contains the world's largest wind tunnel. Designed to test full-scale airplanes and rotorcraft, the test section can achieve speeds of $50 \mathrm{~m} / \mathrm{s}(112 \mathrm{mph})$. Rigorous control of inflow conditions was the overriding consideration that mandated wind tunnel testing of the wind turbine. Although it is quite large, the wind tunnel possesses excellent test section flow quality. Flow speed deviates no more than $0.25 \%$ from the nominal value, whereas the flow velocity vector diverges no more than $0.5^{\circ}$ from the test section axis. Turbulence intensity (streamwise component) is typically no greater than $0.5 \%$. These and other pertinent data have been characterized and documented in detail by Zell. [7] 
Accordingly, test section speed was set and maintained within close tolerances to nominal values.

Figure 1 contains representative 30 -second test section speed records for nominal speeds of 5, 10, 15, 20, and $25 \mathrm{~m} / \mathrm{s}(11-56 \mathrm{mph})$. These test section speeds were acquired for all data sets throughout the experiment, and were measured by NASA's air data system installed in the wind tunnel. [7] Typically, the set speed value differed less than $0.1 \mathrm{~m} / \mathrm{s}(0.2 \mathrm{mph})$ from the nominal value. The standard deviations (SDs) shown near the right-hand side of the plot represent standard deviation about the mean of the actual speed record. Elevated standard deviations at lower speeds represent measurement system uncertainties at low pressure levels, not actual increases in test section speed standard deviation.

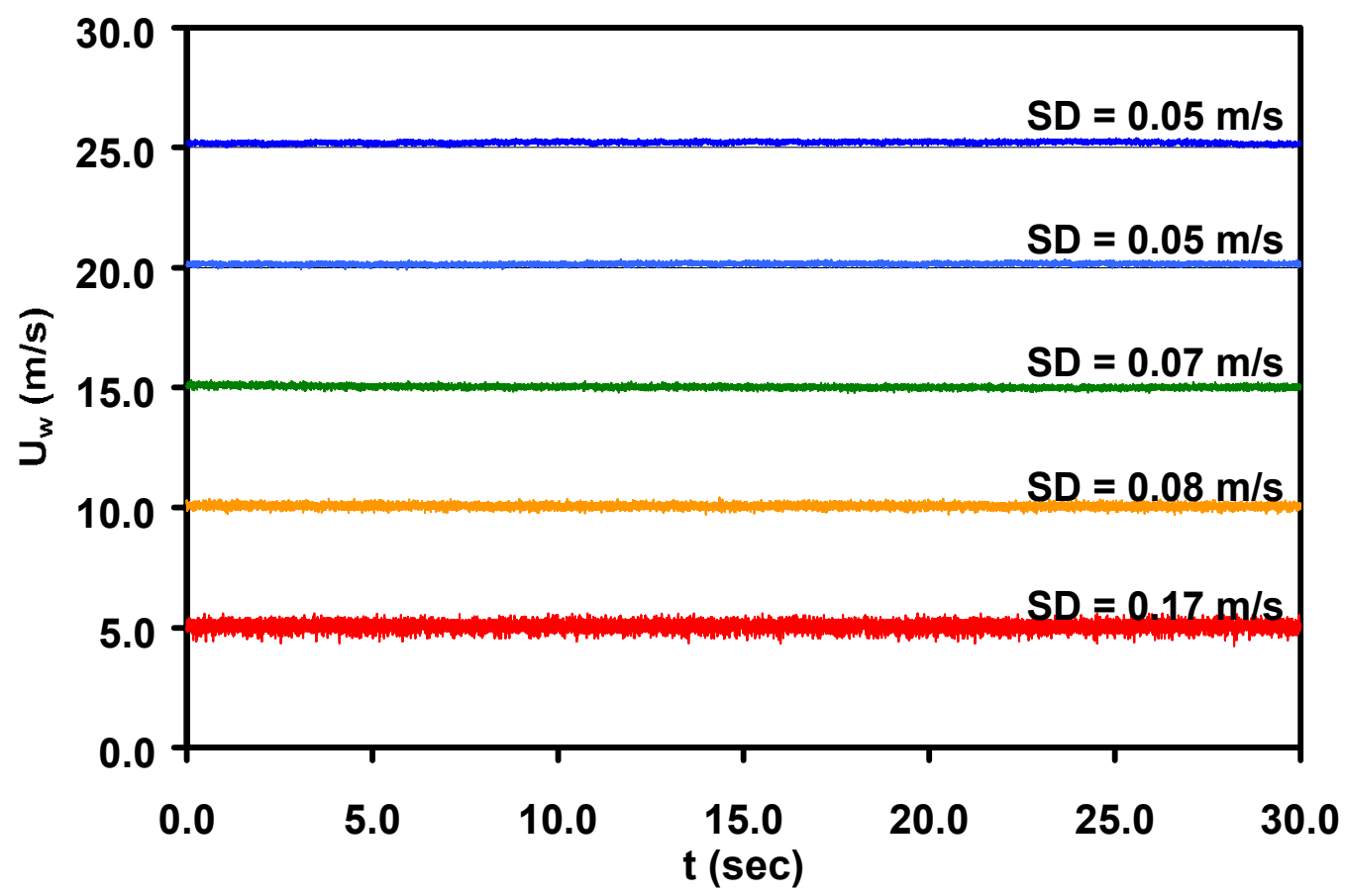

Figure 1. Representative test section speed records for nominal speeds of $5,10,15,20$, and 25 $\mathrm{m} / \mathrm{s}$. Standard deviations in speed are annotated for each record.

Test section size was a key factor in selecting this wind tunnel for the subject experiment. The 24.4-m (80') by 36.6-m (120') test section allowed the $10 \mathrm{~m}$ (33') in diameter UAE turbine (both shown schematically in the inset of Figure 2) to be tested with minimal blockage effects. A method derived by Glauert [8] for propeller testing was adapted for wind turbines, and applied for the UAE in the test section. The results are presented graphically in Figure 2 for blade pitch angles of $0^{\circ}, 3^{\circ}$, and $6^{\circ}$.

In Figure 2, the quantity $\mathrm{U}_{\mathrm{W}, \mathrm{TUN}} / \mathrm{U}_{\mathrm{W}, \mathrm{ATM}}$ represents the ratio of test section speed $\left(\mathrm{U}_{\mathrm{W}, \mathrm{TUN}}\right)$ to test section speed required to achieve the same turbine performance in the absence of the test section boundaries $\left(\mathrm{U}_{\mathrm{W}, \mathrm{ATM}}\right)$. This ratio represents the magnitude of the wake induction influence in the presence of the test section boundaries. This quantity remains substantially less than $1 \%$ for most test conditions, indicating that blockage is of negligible concern for these experiments. 


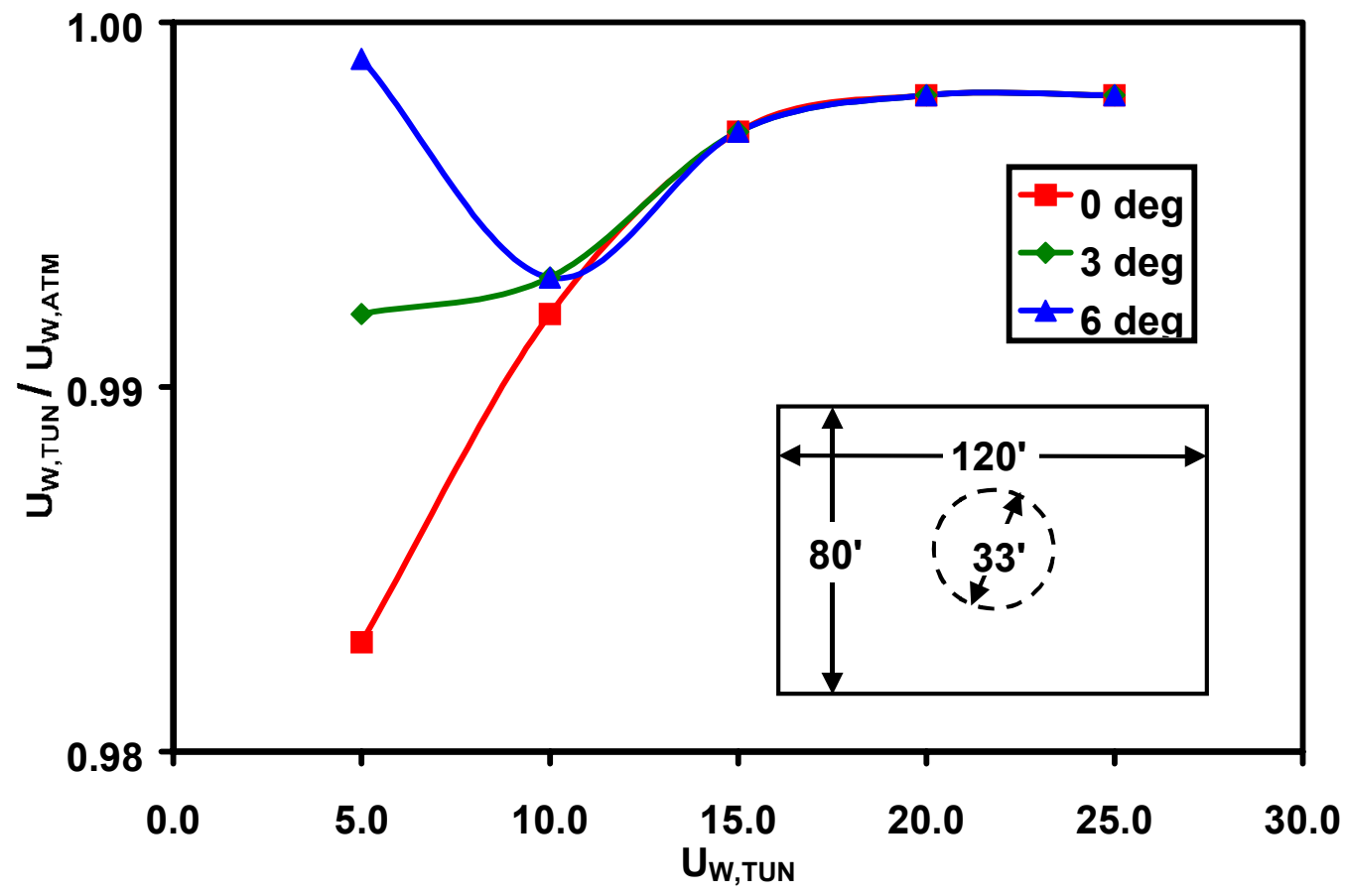

Figure 2. Blockage estimate for the UAE in the NASA-Ames 24.4-m (80') by 36.6-m (120') wind tunnel. Results are shown for blade pitch angles of 0,3 , and $6^{\circ}$.

\section{Examples of Data Quality and Reliability}

Data acquired via the UAE during the wind tunnel test were both accurate and repeatable. As with all experiments, there are measurement uncertainties associated with the wind tunnel test data. It is very difficult to express these uncertainties in a practical way that is comprehensive to all data users. This section is intended to provide some basic insight into wind tunnel test data quality.

Data systems used on the UAE had been proven through many years of field testing. Previous results have been examined and scrutinized in over 100 published reports. To ensure that required data accuracy levels were maintained during the wind tunnel test, separate and independent pressure measurement systems were used by NREL and NASA. Comparison of resulting data show nearly identical results. For example, when all upwind test cases are averaged, the greatest difference in tunnel dynamic pressure measured on the rotating turbine blades by NREL, as compared to the same parameter measured upwind of the turbine by NASA, was 5.5 pascals $(0.0008 \mathrm{psi})$. This indicates that the average pressure measurement system bias error was less than $0.22 \%$ of full-scale throughout operation. This is well within measurement accuracy levels required for most analyses utilizing aerodynamic pressure coefficient data.

This technique of using many redundant data systems to cross-check incoming values was maintained throughout testing to continuously ensure required levels of accuracy. Results show remarkable data repeatability, as data sets taken weeks apart are virtually identical. NREL attributes much of the accuracy to the on-board pressure calibration system that was used to re-calibrate all 155 blade-mounted pressure transducers each half-hour of operation. This system was developed and used extensively in the field, where extreme ambient temperature variations made it essential to keep the temperature-sensitive pressure transducers within calibration specification. Because ambient temperature variations were minimal in the wind tunnel, even higher levels of accuracy were obtained. 
Figure 3 shows representative angle-of-attack data from 36 consecutive blade rotation cycles for all five span stations. The uppermost plot represents the 0.34R station, and successively lower plots correspond to the $0.51 \mathrm{R}, 0.67 \mathrm{R}, 0.84 \mathrm{R}$, and $0.91 \mathrm{R}$ stations, respectively. Angle of attack was derived from five-hole probe inflow angles using an experimentally derived upwash correction. [1] At a blade azimuth of $0^{\circ}$, the instrumented blade is located at the 12 o'clock position. Test section speed for these data was $13 \mathrm{~m} / \mathrm{s}(29$ $\mathrm{mph}$ ) and yaw angle was $30^{\circ}$. Because the turbine is operating in yaw, angle of attack varies with blade azimuth in approximate sinusoidal fashion at all five span locations. The plot corresponding to each span location consists of 36 individual traces, which are indistinguishable because of the remarkable repeatability from one cycle to the next.

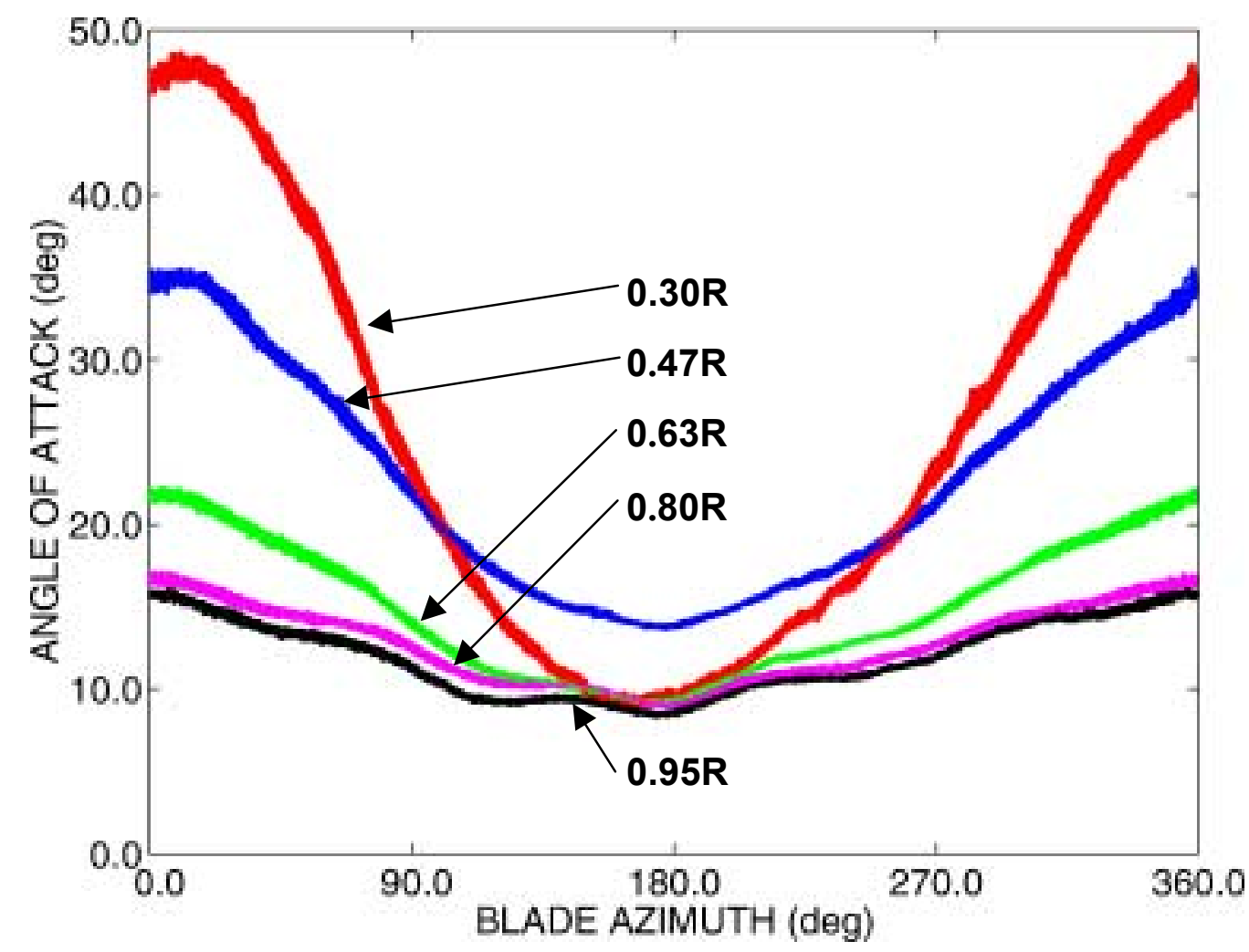

Figure 3. Representative angle of attack data from 36 consecutive blade rotation cycles, for all five span stations. Test section wind speed $=13 \mathrm{~m} / \mathrm{s}$, yaw angle $=30^{\circ}$

Figure 4 contains normal aerodynamic force coefficient $\left(C_{n}\right)$, tangent aerodynamic force coefficient $\left(C_{t}\right)$, and pitching-moment aerodynamic force coefficient $\left(\mathrm{C}_{\mathrm{m}}\right)$ records from $0.30 \mathrm{R}$ as a function of angle of attack, for 36 consecutive blade rotation cycles. Mean $C_{n}, C_{t}$, and $C_{m}$ also are shown, appearing as thin black traces passing through the approximate centers of the three data ensembles. Test section speed for these data was $13 \mathrm{~m} / \mathrm{s}(29 \mathrm{mph})$ and yaw angle was $30^{\circ}$. At angles of attack above static stall, where unsteady separation dominates the flow field, significant cycle-to-cycle variation and deviation about the mean are evident, as expected. However, at angles of attack below static stall $\left(<15^{\circ}\right)$, where the flow is largely attached and little cycle-to- cycle variation occurs, data records corresponding to the 36 individual cycles agree closely and remain near the mean. In the absence of cycle-to-cycle variation imposed by flow-field fluctuations, close cycle-to-cycle agreement provides further compelling evidence of data repeatability and measurement system stability. 


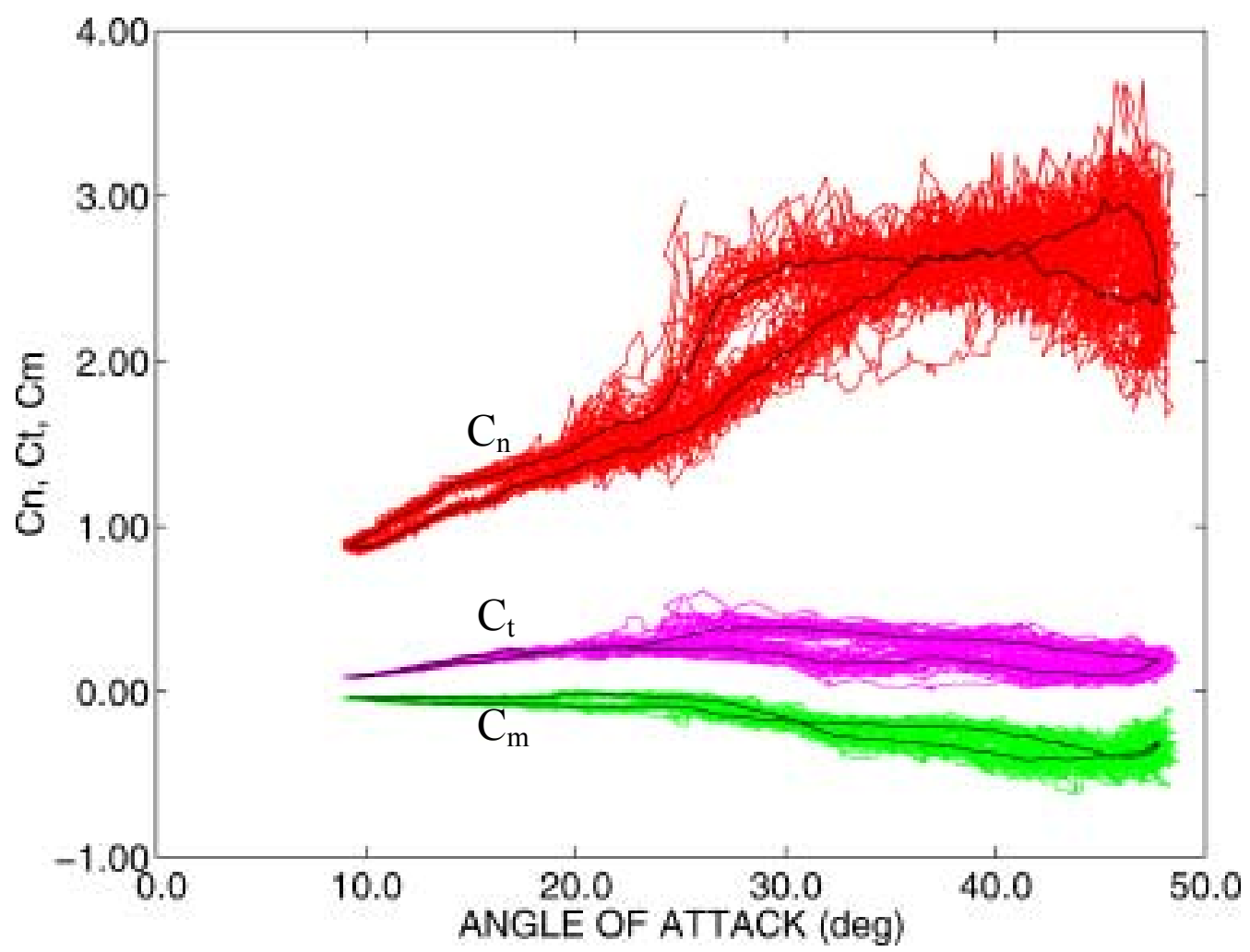

Figure 4. $C_{n}, C_{t}$, and $C_{m}$ records as a function of angle of attack for 36 consecutive blade rotation cycles at $0.30 R$. Test section wind speed $=13 \mathrm{~m} / \mathrm{s}$, yaw angle $=30^{\circ}$

Trends observed in force and moment coefficient data were reflected in instantaneous surface-pressure distributions. Figure 5 contains instantaneous surface-pressure distributions from $0.47 \mathrm{R}$, for 36 consecutive blade rotation cycles. The top panel corresponds to an instantaneous blade azimuth angle of $0^{\circ}$ (12 o'clock position), whereas the bottom panel represents an instantaneous blade azimuth angle of $180^{\circ}$ (6 o'clock position). Test section speed for these data was $13 \mathrm{~m} / \mathrm{s}(29 \mathrm{mph})$ and yaw angle was $30^{\circ}$.

In the upper panel of Figure 5, significant cycle-to- cycle variation is apparent in the suction surfacepressure distributions. This variation is due to unsteady separation and the presence of a dynamic-stall vortex, shown by the pressure coefficient $\left(\mathrm{c}_{\mathrm{p}}\right)$ minima at $\mathrm{x} / \mathrm{c}=0.36$. However, unsteady separation exercises no direct influence on the blade's positive pressure surface, and surface pressures there exhibit strong cycle-to-cycle repeatability. In the lower panel of Figure 5, instantaneous angle of attack is low, the flow field is temporarily attached, and the surface pressures are repeatable. As with the force and moment coefficient records, surface- pressure data exhibit very close cycle-to-cycle repeatability unless unsteadiness in the flow field precludes it. Data in Figures 3, 4, and 5 show extremely close agreement over 36 blade rotation cycles, unless disrupted by unsteadiness in the flow field. This provides strong evidence of data repeatability and system stability during the time required for 36 blade rotation cycles, which is typically 30 seconds. However, Figure 6 demonstrates that data are repeatable, and that the measurement system was thus stable over substantially longer time periods. 

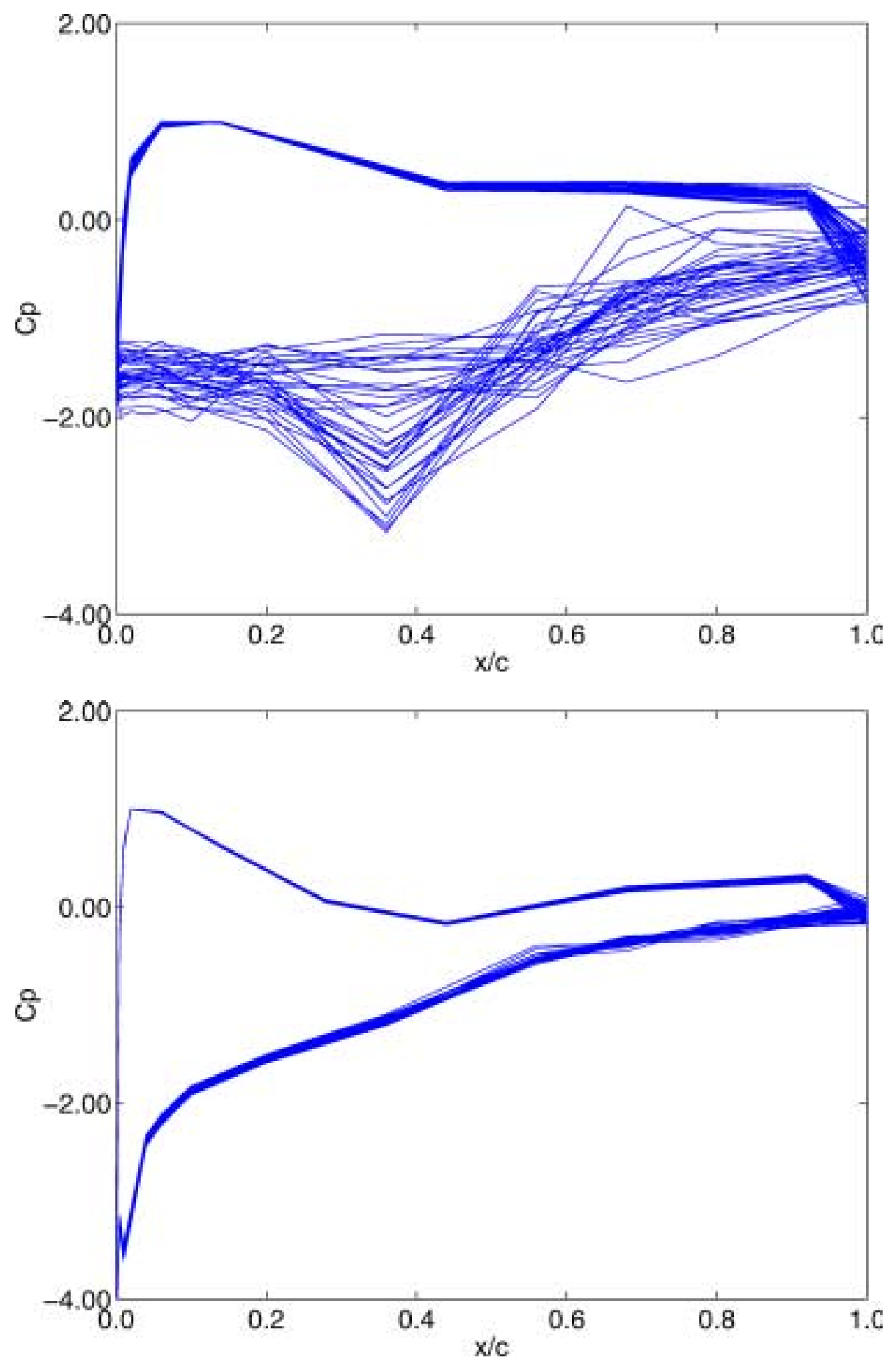

Figure 5. Instantaneous $c_{p}$ distributions from $0.47 R$, for 36 consecutive blade rotation cycles. Top panel: azimuth angle $=0^{\circ}$. Bottom panel: azimuth angle $=180^{\circ}$. Test section wind speed $=13 \mathrm{~m} / \mathrm{s}$, yaw angle $=30^{\circ}$ 
Each panel in Figure 6 contains 36 snapshots (from the 12 o'clock azimuth position) of surface- pressure data from two different $0.47 \mathrm{R}$ data sets. In each panel, the two surface-pressure distributions have been slightly displaced in the $(\mathrm{x} / \mathrm{c})$ direction to allow them to be distinguished from each other. All data in Figure 6 correspond to a test section speed of $9 \mathrm{~m} / \mathrm{s}(20 \mathrm{mph})$ and a yaw angle of $0^{\circ}$, ensuring that flowfield unsteadiness will not disrupt repeatability. The two surface-pressure distributions in the upper panel were acquired approximately 21 minutes apart, whereas the two surface pressure distributions in the lower panel were acquired one week apart. The remarkable conformity from hour to hour and week to week provides indisputable proof of the repeatability of the pressure data acquired during this wind tunnel experiment and for the stability of the measurement system.

Comparisons involving UAE data separated by varying elapsed times were extremely useful for assessing measurement system stability and data repeatability. To evaluate measurement system and data accuracy, UAE measurements of test section flow quantities were compared with measurements of these same quantities acquired via the air data system resident in the wind tunnel test section. [7] 

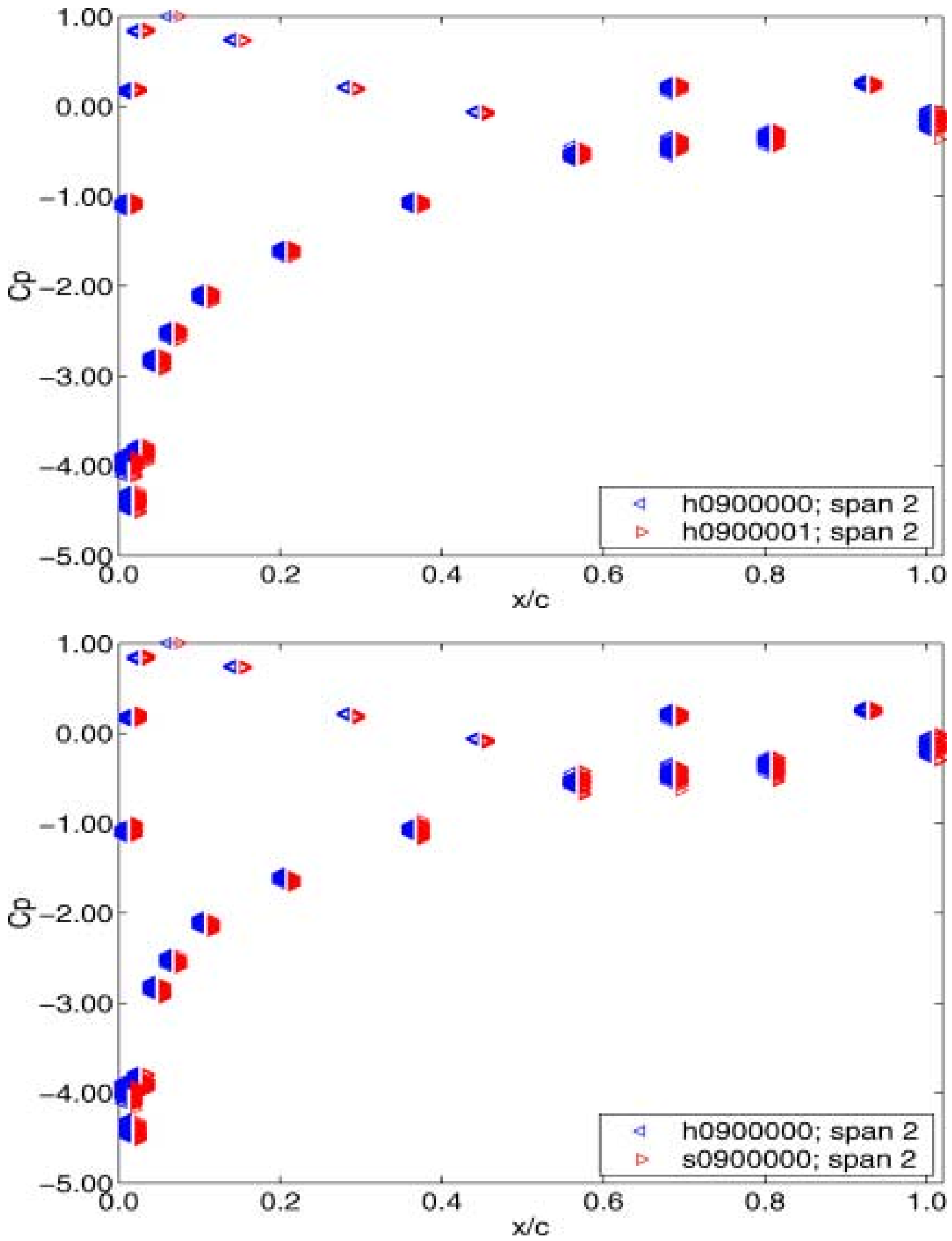

Figure 6. Each panel contains 36 cycles of surface pressure data from two different data sets. Data sets in top panel were acquired 21 minutes apart; data sets in bottom panel were taken one week apart. (Tap locations relative to $x / c$ axis in both plots were shifted slightly for display clarity.) Test section speed $=9 \mathrm{~m} / \mathrm{s}$, yaw angle $=0^{\circ}, 0.47 \mathrm{R}$ 
To accomplish this, the UAE instrumented blade was pitched such that the local angle of attack was less than $8^{\circ}$ at all five span locations. Then, the blade was parked consecutively at both horizontal $\left(90^{\circ}\right.$ and $270^{\circ}$ ) azimuth positions. At each blade azimuth position, the test section total pressure was taken from the blade surface-pressure tap having the highest pressure. [9] This procedure was repeated for three test section speeds, $15.9 \mathrm{~m} / \mathrm{s}(35.6 \mathrm{mph}), 21.2 \mathrm{~m} / \mathrm{s}(47.4 \mathrm{mph})$, and $26.5 \mathrm{~m} / \mathrm{s}(59.3 \mathrm{mph})$. These data are presented in Figure 7.

In Figure 7, test-section total pressure, measured by the wind tunnel air data system at the three test section speeds, is indicated by the three horizontal dashed lines extending across the graph. The symbols represent the test section total pressure measured by the UAE at $0.30 \mathrm{R}, 0.47 \mathrm{R}, 0.63 \mathrm{R}, 0.80 \mathrm{R}$, and $0.95 \mathrm{R}$. Notably, UAE total pressure measurements and NASA air data system measurements differ by no more than 10 pascals ( 0.0015 pounds per square inch [psi]) for these parked-blade data sets. And, at most span stations, the difference between the two is substantially less than 10 pascals.

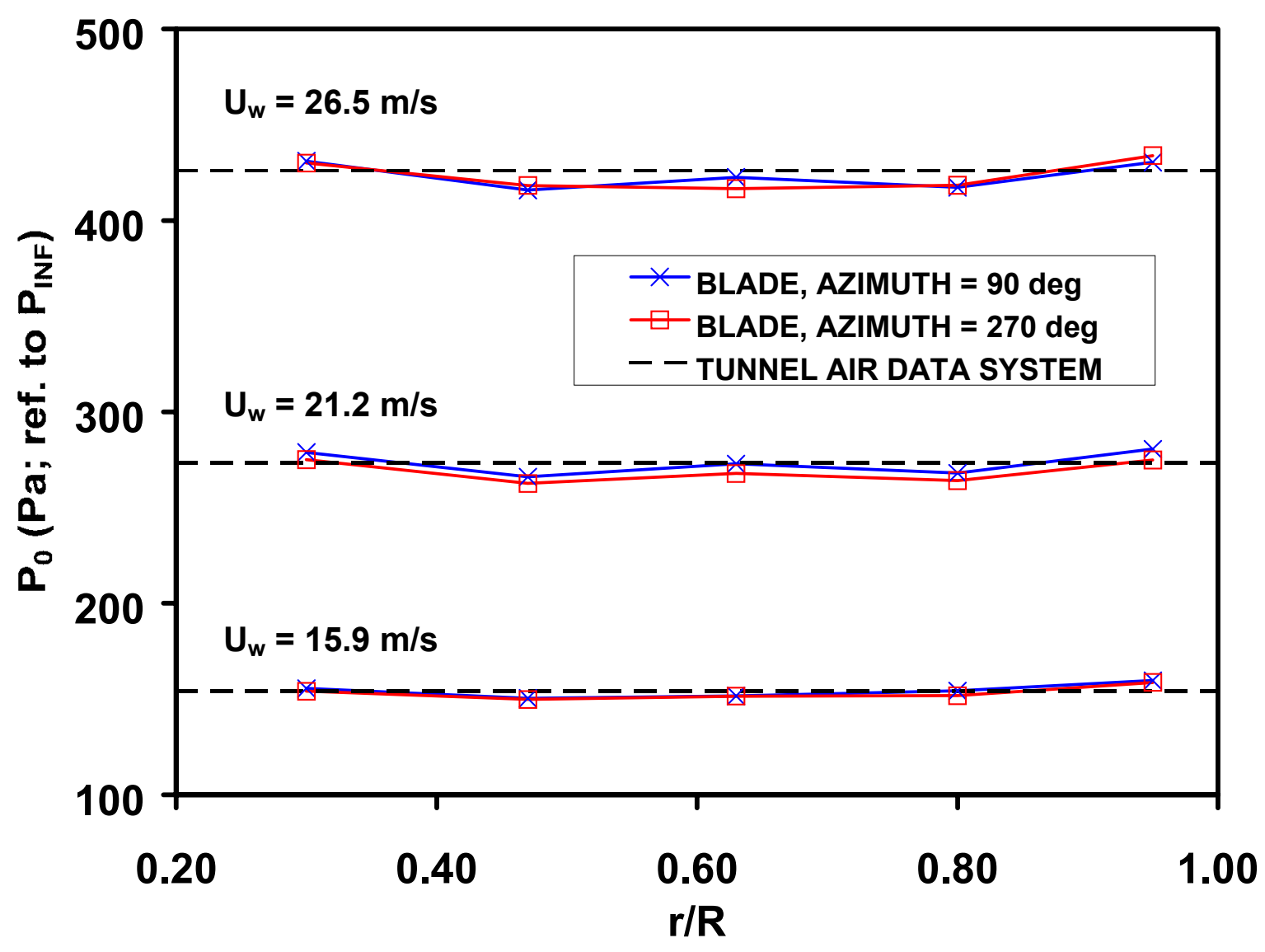

Figure 7. Comparison between test section total pressure data acquired via UAE instrumentation system versus NASA-Ames wind tunnel air data system

\section{Blind-Comparison Objectives and Background}

We undertook the blind comparison to better understand uncertainties associated with wind turbine model predictions. Predictions include the effects of both the modeler and modeling tool. All modelers were provided with the exact same detailed turbine description, including results of various 2-D wind tunnel tests of the S809 airfoils used on the NREL wind turbine. 
The experts who participated in the blind comparison were provided detailed turbine specifications (via a Web site) sufficient to build their models. Results required were mostly aerodynamic parameters, such as components of lift and drag along the blade span. We were surprised at the level of participation because a significant amount of work was needed to build the models and produce the resulting huge volume of required output data. It was also risky because participants did not know the results in advance. To minimize risk of unfavorable criticism or potential embarrassment, NREL decided to maintain anonymity in published results, and therefore modeler results are not labeled on plots shown below. Instead, we grouped results into four basic modeling-tool categories to facilitate comparison: performance codes, aeroelastic codes, wake codes, and CFD (computational fluid dynamics) codes. The assignment was somewhat arbitrary and subjective because some models use combinations of methodologies. The codes and their assigned model types are listed in Table 1. The participants supplied very specific descriptions of all codes used in the blind comparison, and further detailed information can be obtained from the authors.

All participants compiled their predictions into large Excel spreadsheet files and e-mailed them to NREL. NREL assembled and processed the information into plots comparing participants' predictions with corresponding measured wind tunnel data. At the subsequent Science Panel meeting, specific flow phenomena important to wind turbine aerodynamics were highlighted. These included operating in offyaw conditions (dynamic stall), tower wake interaction, and 3-D rotational effects (delayed stall inboard and tip loss outboard). 
Table 1. Blind-Comparison Participants and Modeling Codes Used

\begin{tabular}{|c|c|c|c|c|}
\hline Participant & Organization & Code Name & $\begin{array}{l}\text { Code } \\
\text { Type }\end{array}$ & Code Description \\
\hline $\begin{array}{l}\text { Michael Selig } \\
\text { Philippe Giguere }\end{array}$ & University of Illinois & $\begin{array}{l}\text { PROPID-C } \\
\text { PROPID-UI }\end{array}$ & $\begin{array}{l}\text { Performance } \\
\text { Performance }\end{array}$ & $\begin{array}{l}\text { Performance model with BEM and Corrigan stall delay model } \\
\text { Performance model with BEM and UIUC stall delay model }\end{array}$ \\
\hline $\begin{array}{l}\text { Martin Hansen Takis } \\
\text { Chaviaropoulos }\end{array}$ & $\begin{array}{l}\text { Tech Univ of Denmark/ } \\
\text { CRES Greece }\end{array}$ & ROTABEM & Performance & $\begin{array}{l}\text { Performance model with BEM using 3-D corrected airfoil data based on a quasi-3D } \\
\text { Navier-Stokes solver }\end{array}$ \\
\hline $\begin{array}{l}\text { David Malcolm, Tim } \\
\text { McCoy, Dayton Griffin }\end{array}$ & Global Energy Concepts & ADAMS & Aeroelastic & Multi-body aeroelastic model using "AeroDyn" aerodynamics (BEM/Leishman-Beddoes) \\
\hline James Shawler & $\begin{array}{l}\text { Loughborough University } \\
\text { CREST UK }\end{array}$ & YAWDYN & Aeroelastic & $\begin{array}{l}\text { Aeroelastic model with rigid blade flapping hinge blade using "AeroDyn" aerodynamics } \\
\text { (BEM/Leishman-Beddoes) }\end{array}$ \\
\hline $\begin{array}{l}\text { Craig Hansen, } \\
\text { Dave Laino }\end{array}$ & Windward Engineering & $\begin{array}{l}\text { ADAMS-1 } \\
\text { ADAMS-2 } \\
\text { ADAMS-3 }\end{array}$ & $\begin{array}{l}\text { Aeroelastic } \\
\text { Aeroelastic } \\
\text { Aeroelastic }\end{array}$ & $\begin{array}{l}\text { Multi-body aeroelastic model using "AeroDyn" aerodynamics (equilibrium wake, } \\
\text { BEM/Leishman-Beddoes) } \\
\text { Same except "AeroDyn" with dynamic inflow, BEM/Leishman-Beddoes } \\
\text { Same except "AeroDyn" with dynamic inflow and delayed stall, BEM/Leishman-Beddoes }\end{array}$ \\
\hline $\begin{array}{l}\text { Robert Rawlinson - } \\
\text { Smith }\end{array}$ & Garrad-Hassan & BLADED & Aeroelastic & Assumed modes aeroelastic model with BEM/Beddoes-Leishman aerodynamics \\
\hline Wayne Johnson & NASA Ames & Camrad II & Aeroelastic & Aero-mechanical rotorcraft analysis tool \\
\hline Helge Madsen & Risoe & $\begin{array}{l}\text { HawC } \\
\text { HawC-3D }\end{array}$ & $\begin{array}{l}\text { Aeroelastic } \\
\text { Wake }\end{array}$ & $\begin{array}{l}\text { Aeroelastic model with BEM theory } \\
\text { Aeroelastic model with 3D CFD actuator disc model }\end{array}$ \\
\hline $\begin{array}{l}\text { Herman Snel, } \\
\text { Koert Lindenburg }\end{array}$ & $\mathrm{ECN}$ & PHATAS & Aeroelastic & Aeroelastic model with BEM theory \\
\hline $\begin{array}{l}\text { Biorn Montgomerie, } \\
\text { Anders Biorck, } \\
\text { Hans Ganander }\end{array}$ & $\begin{array}{l}\text { FFA/ Nordic Windpower/ } \\
\text { Teknikgruppen }\end{array}$ & VIDYN & Aeroelastic & $\begin{array}{l}\text { Aeroelastic code with "AerForce" aerodynamics and "DynStall" dynamic stall } \\
\text { (BEM/Leishman-Beddoes) }\end{array}$ \\
\hline Niels Sorensen & Risoe & EllipSys3D & CFD & 3D incompressible Navier-Stokes model \\
\hline Robert Mikkelsen & Tech.Univ. of Denmark & ADDWANS & CFD & Combined Navier-Stokes BEM approach \\
\hline $\begin{array}{l}\text { Lakshmi Sankar } \\
\text { Guanpeng Xu }\end{array}$ & Georgia Tech & Hybrid CFD & CFD & 3D multi-domain analysis unsteady Navier-Stokes model \\
\hline $\begin{array}{l}\text { Michael Belessis } \\
\text { Spyros Voutsinas }\end{array}$ & CRES-NTUA & GENUVP & Wake & Vortex element, free wake model \\
\hline $\begin{array}{l}\text { Frank Coton, } \\
\text { Tongguang Wang, } \\
\text { Roddy Galbraith }\end{array}$ & University of Glasgow & HawtDawg & Wake & $\begin{array}{l}\text { Prescribed wake model (Horizontal Axis Wind Turbine Directly Allocated Wake } \\
\text { Geometry) }\end{array}$ \\
\hline Gerard Van Bussel & Tech. Univ. of Delft & PREDICDYN & Wake & Asymptotic acceleration potential model \\
\hline $\begin{array}{l}\text { Michael Belessis } \\
\text { Spyros Voutsinas }\end{array}$ & CRES-NTUA & NS3D & & 3D steady RANS finite volume formulation, Chimera mesh \\
\hline
\end{tabular}




\section{Summary of Blind-Comparison Results}

This discussion initially focuses on two key parameters, rotor torque and blade bending, in order to summarize the cumulative effect of aerodynamic responses on the results. Both parameters are directly affected by aerodynamic forces acting along the blade. The aerodynamic forces acting along the blade can be resolved into those producing torque (thus power) and those producing blade bending moments. Therefore, in order to look at the cumulative effect of the discrepancies observed in the blind-comparison predictions, plots of these two parameters for the NREL turbine operating in the NASA-Ames tunnel, and corresponding modeler predictions, are shown in Figures 8 and 9. The data in the figures correspond to cases in which the turbine was operated in a simple upwind configuration with no yaw error (e.g., the wind direction is exactly perpendicular to the rotor plane) at tunnel wind speeds of $7,10,13,15,20$, and $25 \mathrm{~m} / \mathrm{s}$ (16 to $56 \mathrm{mph}$ ). Each figure contains four plots, each showing prediction results for a different code type. In all plots, wind tunnel test data are shown as a thicker curve with dark, solid symbols. Anonymous modeler predictions are shown with thinner lines and open or shaded symbols. Results are grouped into code categories to enable relative comparisons within code type. Symbols identifying predictions from a specific model are consistent between plot types. For example, the same code is identified with the ${ }^{*}$ symbol in the aeroelastic plots of both Figure 8 and Figure 9 . Upon closer examination, a comparison of plot data shows that this particular aeroelastic code did a good job of predicting rotor torque, especially at the lower wind speeds, but did a poor job of predicting blade bending.

Both Figures 8 and Figure 9 show huge variations among participant results. Discrepancies tend to increase with wind velocity. The wind tunnel test data often represent the average of the modelers' results. It was therefore difficult for the modelers to blame uncertainties in experimental results for the observed discrepancies. One area of concern is at $7 \mathrm{~m} / \mathrm{s}(16 \mathrm{mph})$, the speed at which stall is not occurring anywhere on the blade. This region of operation represents relatively simple aerodynamic responses, and should be the easiest and most straight-forward for the modeling tools to reproduce. This was obviously not the case, and the modelers were surprised that their results did not agree better in this region. Turbine power predictions ranged from $25 \%$ to $175 \%$ of measured, and blade bending-force predictions ranged from $85 \%$ to $150 \%$ of measured. Participants surmised that discrepancies were probably due to different modeler assumptions on how to use the 2-D airfoil data and extrapolate it to 3-D. Even at lower wind velocities, most modelers tended to over-predict blade bending.

Another concern is the increased data scatter at higher wind velocities. In Figure 8 (page 21), at a wind tunnel velocity of $20 \mathrm{~m} / \mathrm{s}(45 \mathrm{mph}$ ), most of the blade (from the root to $0.80 \mathrm{R}$ ) is operating in stall. Power predictions at this velocity range from $30 \%$ to $250 \%$ of the measured value. In Figure 9 (page 22), at 25 $\mathrm{m} / \mathrm{s}(56 \mathrm{mph})$ velocity, blade-bending predictions range from $75 \%$ to $150 \%$ of the measured value. This highlights potential sources of problems in successfully designing stall-controlled wind turbines. [4] One European participant noted that the tendency in the European wind industry has been to move away from stall-controlled designs in favor of pitch-controlled designs because of difficulty in predicted loads for stall-controlled turbines. Obviously, more work is needed in model improvement if stall-controlled designs are to be further explored; modelers should exercise extreme caution in using the existing models to predict stall behavior.

Figures 8 and 9 show the cumulative effect of the individual blade span aerodynamic measurements. Detailed plots in this report show all contributing underlying aerodynamic- pressure coefficient measurements. These provide detailed aerodynamic-behavior information at the five instrumented stations $(0.30 \mathrm{R}, 0.47 \mathrm{R}, 0.63 \mathrm{R}, 0.80 \mathrm{R}$, and $0.95 \mathrm{R})$ along the blade. When these plots are examined in detail, it is interesting to note that sometimes the modelers tend to overpredict aerodynamic forces on the inboard part of the blade, while underpredicting the forces outboard. These two errors are offsetting, thus 
enabling the modelers to luckily predict the correct resultant power or bending. However, should a blade designer use the incorrect span-loading estimates, the resulting blade structure would not be optimum.

One code was outstanding in predicting turbine performance and loads under zero-yaw conditions. This code was a 3-D incompressible Navier-Stokes CFD model. It consistently did the best job of predicting aerodynamic forces distributed along the blade span, even under highly three-dimensional and extreme stall conditions. However, CFD models in general are inherently complex and difficult to build, and limited in capability. This particular CFD model of the NREL turbine was only able to simulate the simplest upwind zero-yaw cases, and it took days of computer time to run one case. It could not handle the downwind cases, or operate under yawed flow conditions. Therefore, only a few of the required test cases could be provided. The modeler also indicated that success with his CFD code tended to vary, possibly depending on airfoil type. He said that he had very good luck in this effort with the S809 airfoil [10] used by NREL on the UAE, but has had poor results with some other airfoils in the past. In general, CFD codes are not yet practical modeling tools for wind turbine design tradeoff studies (e.g., it would be impossible to run typical extreme cases needed to define ultimate lifetime loads). The success of this particular CFD code does indicate that there is probably some potential benefit in pursuing CFD, and that further work in this area is warranted.

There were no clear losers in the blind comparison. All other code predictions were equally inconsistent in that they tended to sometimes predict wind tunnel results under certain conditions, but then failed under other conditions. Often, for a particular test condition, an accurate prediction would be made at one span location, but then erroneous predictions were made at adjacent span locations. The main lesson learned was that a lot of work is still needed on our aerodynamics models. We identified many areas of potential deficiency, which will certainly help in focusing future work. For example, there are probably general trends and conclusions that can be made using basic CFD predictions, which can then be refined via detailed simulations using conventional models.

\section{Aerodynamic Parameters}

Figures 10-27 show model results of various aerodynamic-parameter predictions. In all plots, wind tunnel test data are represented as a thicker curve with dark, solid symbols. Anonymous modeler predictions are shown with thinner lines and open or shaded symbols.

Figures 10-13 show aerodynamic force coefficients and local dynamic pressure as a function of wind speed at the $0.95 \mathrm{R}$ location. On these plots, each solid symbol on the thicker trace represents the mean measured blade force coefficient obtained by averaging approximately 435 samples per blade rotation cycle times 36 consecutive cycles. Data points are from wind tunnel tests at test section wind speeds of 7 , $10,13,15,20$, and $25 \mathrm{~m} / \mathrm{s}(16$ to $56 \mathrm{mph}$ ). All are zero-yaw cases. Figure 10 (page 23) shows normal aerodynamic-force coefficient $\left(\mathrm{C}_{\mathrm{n}}\right)$, Figure 11 (page 24) shows tangent aerodynamic-force coefficient $\left(\mathrm{C}_{\mathrm{t}}\right)$, and Figure 12 (page 25) shows pitching moment aerodynamic-force coefficient $\left(\mathrm{C}_{\mathrm{m}}\right)$. These data were obtained by integrating pressures measured from individual taps around the blade contour at the $0.95 \mathrm{R}$ location as described in [11]. As with cumulative results shown above for torque and blade bending, the modeler predictions of aerodynamic responses also show significant deviation and scatter, which increases with wind velocity. The modelers tend to overpredict normal and tangential aerodynamic forces at the outboard location. This is an indication that the tip-loss models used within the aerodynamic algorithms need further work. Pitching moment estimates deviate significantly in stall. Figure 13 (page 26) shows dynamic pressure measured at the local blade station $\left(\mathrm{Q}_{\text {local }}\right)$, which is obtained from the stagnation pressure tap. Greater variation in estimated local dynamic pressure is evident for the wake codes, which may help modelers to isolate problems in calculating these parameters. 
Similarly, Figures 14-17 (pages 27-30) show results of aerodynamic-performance predictions compared to measured data at the inboard $0.30 \mathrm{R}$ station. At this span location, modelers tend to underpredict the load contribution from aerodynamic forces, especially in the normal-force direction. Most codes do not have algorithms that modify the 2-D airfoil performance data for the inboard blade stations. This is usually an effect that modelers use their experience and intuition to estimate. The results indicate that the modelers probably need to further their knowledge in this area, and work should proceed on developing aerodynamics algorithms to better predict delayed stall and 3-D effects. Flow disturbances around the instrumentation enclosures on the UAE rotor hub in the upwind cases, and nacelle in the downwind cases, could also create unusual and unpredictable flow conditions. Such disturbances would probably be more significant at the inboard span locations, and certainly makes the job of predicting inboard aerodynamic performance more difficult.

Similarly, Figures 18-21 (pages 31-34) show results of aerodynamic-performance predictions compared to measured data at $0.63 \mathrm{R}$. This region of the blade is probably more likely to exhibit 2-D behavior because it is not affected by outboard tip loss, inboard delayed stall, or strong 3-D effects. However, resulting predictions still do not show good agreement. At this span location, performance code modelers overpredict normal and tangent forces, whereas the wake and CFD modelers underpredict. Aeroelastic code modelers generally underpredict normal forces and overpredict tangent forces in attached flow. Extremely large variations are evident in the post-stall region (above $10 \mathrm{~m} / \mathrm{s}$ ). These deviations could indicate that either the underlying 2-D airfoil data are bad, or that the basic aerodynamics algorithms need significant improvement, or both.

Figures 22-29 (pages 35-42) show how operation in yaw affects aerodynamic response and is indicative of the dynamic-stall model capabilities within the modeling tool's aerodynamics algorithms. Each figure shows aerodynamic response as a function of instrumented blade azimuth angle, where $0^{\circ}$ is the 12 o'clock position. On all of these plots, the thicker black line with solid symbols shows the azimuthaverage of 36 rotations of measured wind tunnel test data. The other thin lines are modeler predictions. Individual code results cannot be followed from figure to figure because the traces are not identified with symbols due to the wide scatter among predictions and difficulty in producing readable plots. Plots that do not contain thin lines indicate that no modelers provided predictions for that particular parameter and case. $C_{n}$ predictions are shown in the upper left plot, $C_{t}$ in the upper right, $C_{m}$ in the lower left, and $\mathrm{Q}_{\text {local }}$ in the lower right. Figures 22 and 23 show how the $0.30 \mathrm{R}$ location responds to operating with a $30^{\circ}$ yaw error at $15 \mathrm{~m} / \mathrm{s}$ tunnel speed. Predictions from the aeroelastic codes are shown in Figure 22, and predictions from the wake codes are shown in Figure 23. In a similar series of display plots, Figures 24 and 25 show how aerodynamic forces at the $0.30 \mathrm{R}$ span location respond to operation under a $60^{\circ}$ yaw error at $15 \mathrm{~m} / \mathrm{s}$. At $60^{\circ}$ yaw error, the instrumentation boom that protrudes upwind from the turbine rotor creates a wake that propagates downwind through the blade passage centered around $90^{\circ}$ azimuth. Therefore, to examine results unaffected by the boom wake interference, we recommended that measured data in the region from approximately $60^{\circ}-120^{\circ}$ azimuth be ignored. In addition, at $15 \mathrm{~m} / \mathrm{s}$ tunnel speed and $60^{\circ}$ yaw, dynamic pressures as low as 10 to $12 \mathrm{~Pa}$ were recorded at $0.30 \mathrm{R}$ for blade azimuth angles around $40^{\circ}$. Although infrequently encountered, these conditions must be cautiously analyzed since pressure measurements, and quantities derived from them, may be adversely impacted by otherwise negligible uncertainties. Figures 26-29 are similar to 22-25, except results are shown for the $0.47 \mathrm{R}$ location.

Figures 30 and 31 show the effect of tower shadow. Normal-aerodynamic-force $\left(\mathrm{C}_{\mathrm{n}}\right)$ predictions at the $0.47 \mathrm{R}$ location are plotted against blade position within the $130^{\circ}-230^{\circ}$ azimuth range $\left(180^{\circ}\right.$ azimuth corresponds to the blade pointing straight down and immediately behind the tower in the $0^{\circ}$ yaw case). Results from both aeroelastic and wake code predictions are combined onto each plot. Each figure shows four different conditions. The upper left plot shows the effect of the induced velocity field upwind of the rotor as affected by the tower in a zero-yaw upwind case. The upper right plot shows downwind zero- 
yaw case predictions. The lower left plots shows a downwind $-20^{\circ}$ yaw case, and the lower right plot shows a downwind $20^{\circ}$ yaw case. Figure 30 (page 43) shows predictions for operating at a wind tunnel speed of $7 \mathrm{~m} / \mathrm{s}$, and Figure 31 (page 44) shows $17 \mathrm{~m} / \mathrm{s}$ wind speed. The upwind tower-induced velocity effect is minimal, and the few codes that attempt to predict it are close. However, predictions of downwind tower wake effects vary widely from measurements, indicating that more work is needed on tower shadow models.

\section{Conclusions}

The NREL/ NASA-Ames wind tunnel testing was completed in May 2000 and was very successful in that almost all data specified by a Science Panel of international wind turbine aerodynamics experts were obtained. Data sets were acquired from a total of over 1,700 different turbine test conditions. Testing yielded exceptional data accuracy and reliability in the absence of experimental artifacts. The data can be considered highly accurate and reliable, and constitute a valuable resource for developing and validating wind turbine aerodynamics codes.

Immediately following the wind tunnel test, a "blind comparison" was undertaken to begin evaluating the capabilities of wind turbine modeling tools. This was a significant collaborative effort on the part of the international wind turbine research community. Wind turbine modeling experts predicted the behavior of selected cases of the NREL wind turbine operating in the NASA-Ames wind tunnel. Blind-comparison results were not favorable. Modelers were surprised by the wide variations between their various code predictions. There were also significant deviations from measured wind tunnel results. More disconcerting was the scatter evident under supposedly easy-to-predict typical turbine operating conditions. For the no-yaw, steady-state, no-stall cases, turbine power predictions ranged from $25 \%$ to $175 \%$ of measured, and blade-bending-force predictions ranged from $85 \%$ to $150 \%$ of measured. Results at higher wind speeds in stall were especially disappointing - power predictions ranged from $30 \%$ to $275 \%$ of measured, and blade-bending predictions ranged from $60 \%$ to $125 \%$ of measured.

\section{Future Plans}

The results of the blind comparison have shown that there are significant problems within existing wind turbine modeling tools and methodologies. To attack these problems, aggressive, targeted exploitation of the NREL/NASA-Ames UAE database is needed. This will not be an easy task. It will require a significant amount of labor and wide range of skills, well beyond our in-house capabilities. We are, therefore, hoping to team up with our Science Panel for help. We are planning a concerted, cooperative work effort with tasks identified to produce needed improvements. Participants will be provided access to the NASA-Ames data in exchange for specified analyses and results. We anticipate that code algorithms will be produced based on empirical or physical relationships derived from the data. These algorithms will be generic (applicable to all types of modeling tools) and shared among participants.

\section{Acknowledgements}

We are very grateful to all the individuals who participated in our Science Panel meetings. Their generous donations of time and effort, and their dedication to improving wind energy technology, helped make the wind tunnel test, and subsequent blind comparison study, a success. Many traveled from all parts of the world to attend meetings at NREL. Many made significant contributions in helping to define the wind tunnel test requirement. Many spent hours to weeks of uncompensated time preparing and 
running computer models for the blind comparison, while at the same time laying their professional reputations on the line. We would particularly like to thank the Science Panel Technical Oversight Committee: Larry Carr and Jim McCroskey of NASA-Ames, Gordon Leishman of the University of Maryland, and Roddy Galbraith of the University of Glasgow, Scotland.

This work was done at the National Renewable Energy Laboratory in support of the U.S. Department of Energy under contract number DE-AC36-99-GO10337.

\section{Bibliography}

[1] Butterfield, C. P.; Musial, W. P.; Simms, D.A. (1992). “Combined Experiment Final ReportPhase I.” NREL/TP-257-4655. Golden, CO: National Renewable Energy Laboratory.

[2] Simms, D.; Hand, M.; Fingersh, L.J.; Jager, D. (1999). "Unsteady Aerodynamics Experiment Phases II - IV Test Configurations and Available Data Campaigns." NREL/TP-500-25950. Golden, CO: National Renewable Energy Laboratory.

[3] Schepers, J.G., et al. (1997). "Final Report of IEA Annex XIV: Field Rotor Aerodynamics." ECN-C-97-027. Petten, The Netherlands: Netherlands Energy Research Foundation.

[4] Rasmussen, F.; Thirstrup, J.; Winkelaar, D.; Rawlinson-Smith, R. (1993). "Response of Stall Regulated Wind Turbines - Stall Induced Vibrations.” Risø-R-691(EN). Roskilde Denmark: Risø National Laboratory.

[5] Simms, D.; Schreck, S.; Hand, M.; Fingersh, L.; Cotrell, J.; Pierce, K.; Robinson, M. (1999). "Plans for Testing the NREL Unsteady Aerodynamics Experiment 10-m Diameter HAWT in the NASAAmes Wind Tunnel.” NREL/TP-5000-27599. Golden, CO: National Renewable Energy Laboratory.

[6] Fingersh, L.; Simms, D.; Hand, M.; Jager, D.; Cotrell, J.; Robinson, M.; Schreck, S.; Larwood, S. (2001). "Wind Tunnel Testing of NREL's Unsteady Aerodynamics Experiment." Prepared for the 39th AIAA Aerospace Sciences Meeting and Exhibit, Reno, NV, January 11-14, 2001, pp. 194-200.

[7] Zell, P. (1993). "Performance and Test Section Flow Characteristics of the National Full-Scale Aerodynamics Complex 80- by 120-Foot Wind Tunnel." NASA TM 103920.

[8] Glauert, H. (1947, reprinted 1993). The Elements of Aerofoil and Wing Theory (2nd. ed.). Cambridge University Press.

[9] Shipley, D.; Miller, M.; Robinson, M.; Luttges, M.; Simms, D. (1995). "Techniques for the Determination of Local Dynamic Pressure and Angle of Attack on a Horizontal Axis Wind Turbine." NREL/TP-442-7393. Golden, CO: National Renewable Energy Laboratory.

[10] Somers, D.M. (1997). Design and Experimental Results for the S809 Airfoil. NREL/SR-4406918. Golden, Colorado: National Renewable Energy Laboratory.

[11] Hand, M.M.; Simms, D.A.; Fingersh, L.J.; Jager, D. W.; Cotrell, J.R.; Schreck, S. J.; Larwood, S.M. (2001). "Unsteady Aerodynamics Experiment Phase VI: Wind Tunnel Test Configurations and Available Data Campaigns.” NREL/TP-500-29955. Golden, CO: National Renewable Energy Laboratory. 


\section{Abbreviations, Conventions, and Nomenclature}
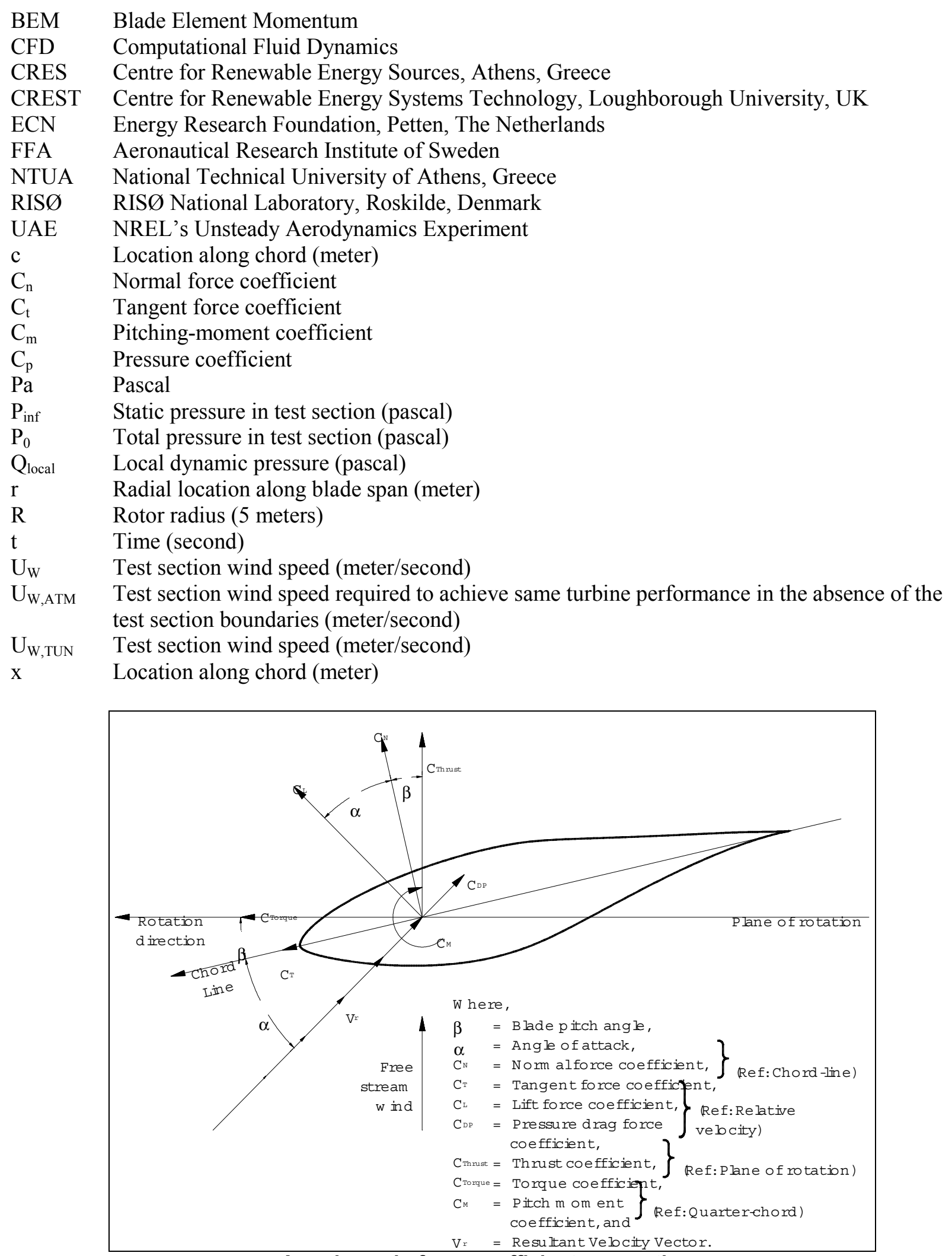

Aerodynamic-force coefficient conventions 

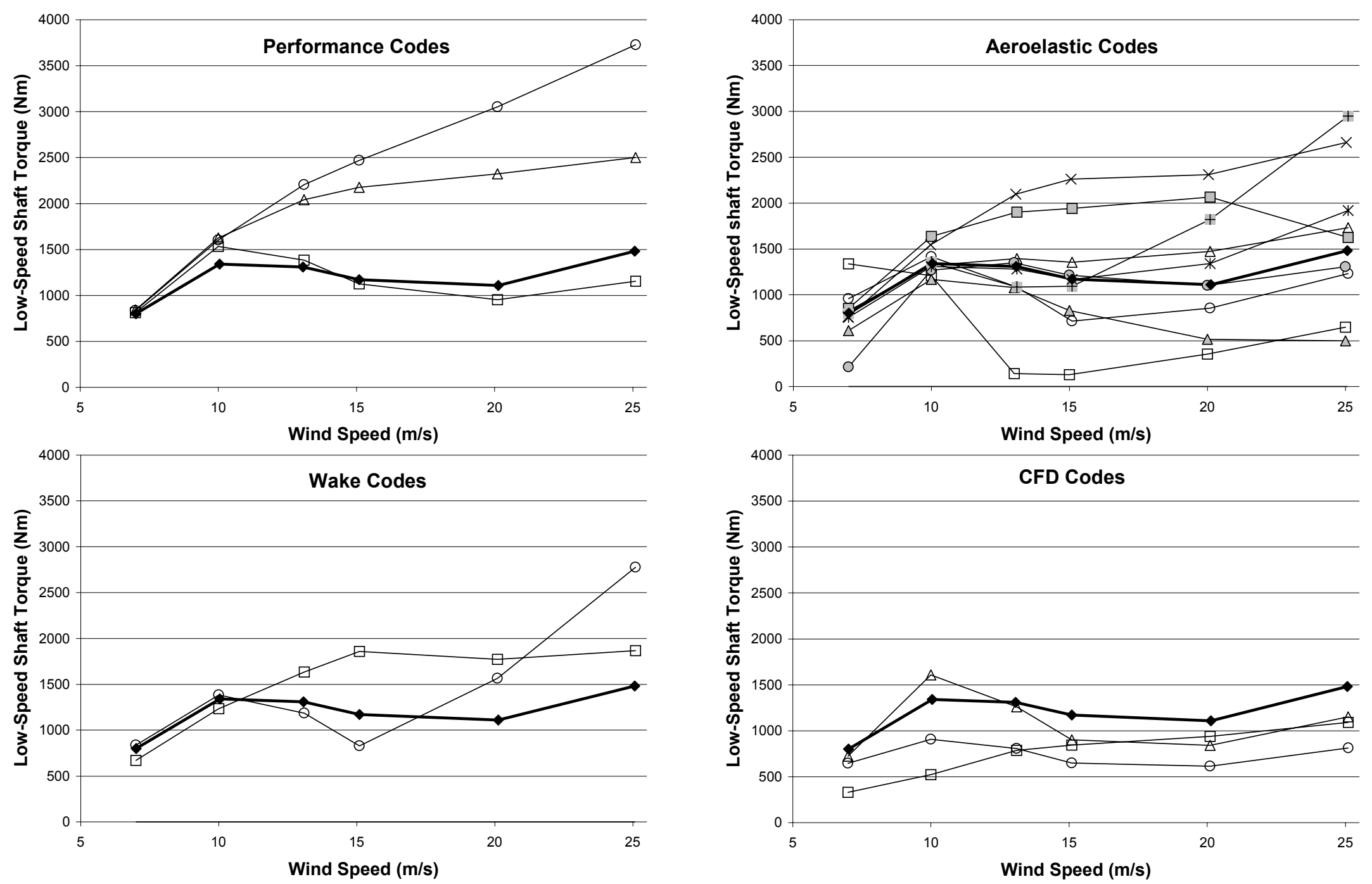

Figure 8. Low-speed shaft torque, upwind, $0^{\circ}$ yaw 

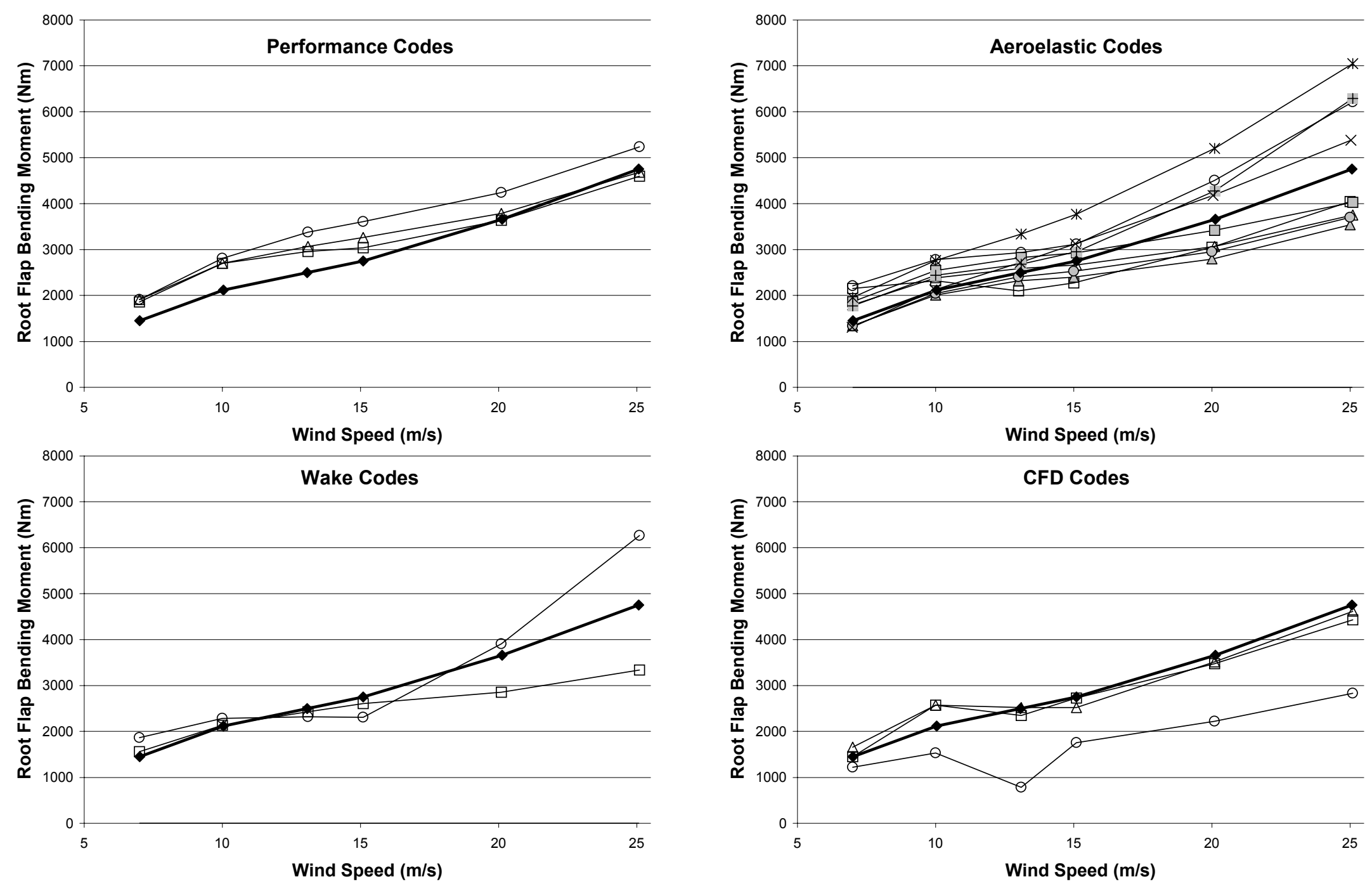

Figure 9. Root flap bending moment, upwind, $0^{\circ}$ yaw 

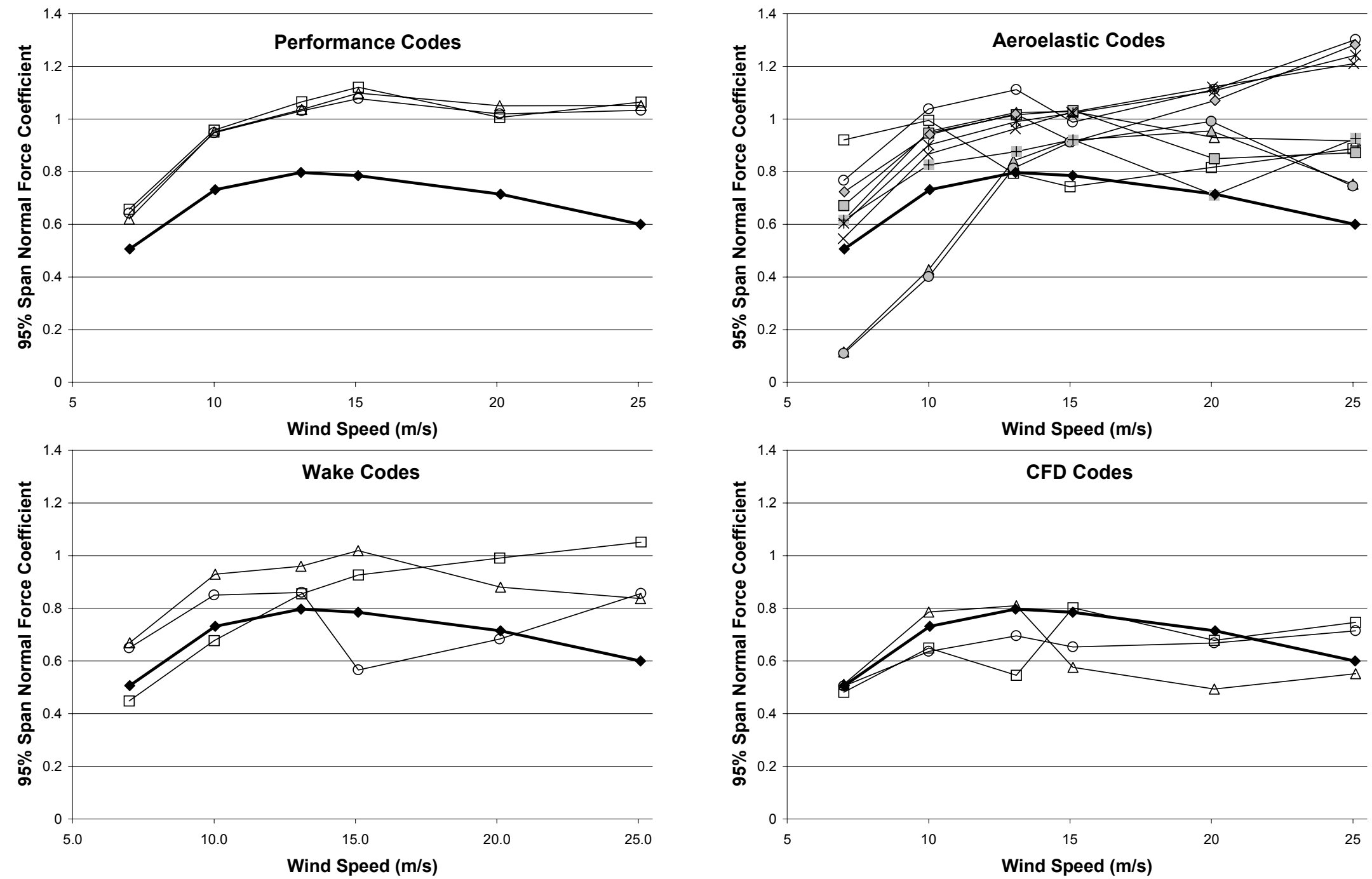

Figure 10. $0.95 R$ normal force coefficient, upwind, $0^{\circ}$ yaw 

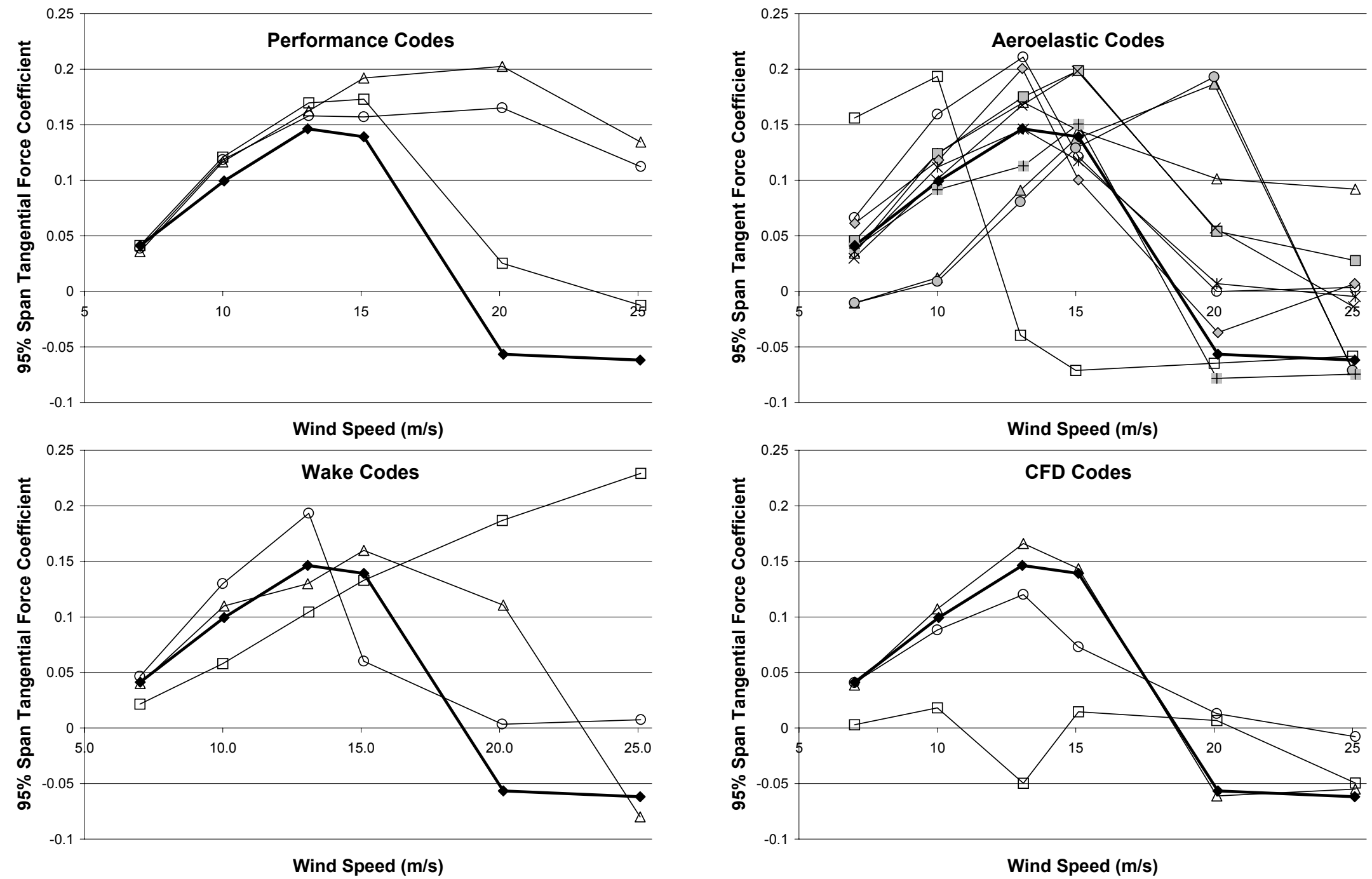

Figure 11. $0.95 \mathrm{R}$ tangent force coefficient, upwind, $0^{\circ}$ yaw 

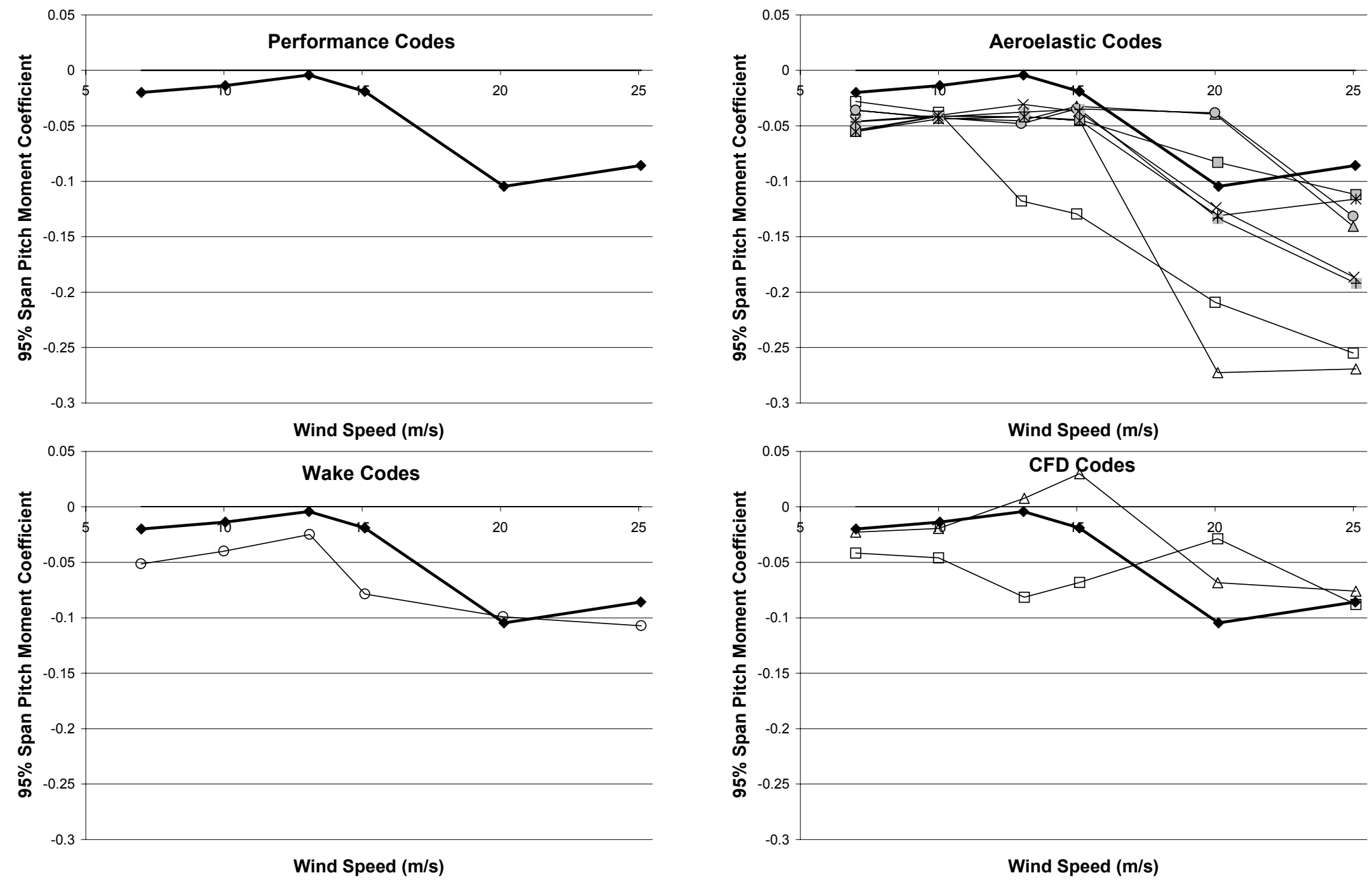

Figure 12. $0.95 R$ pitch moment coefficient, upwind, $0^{\circ}$ yaw 

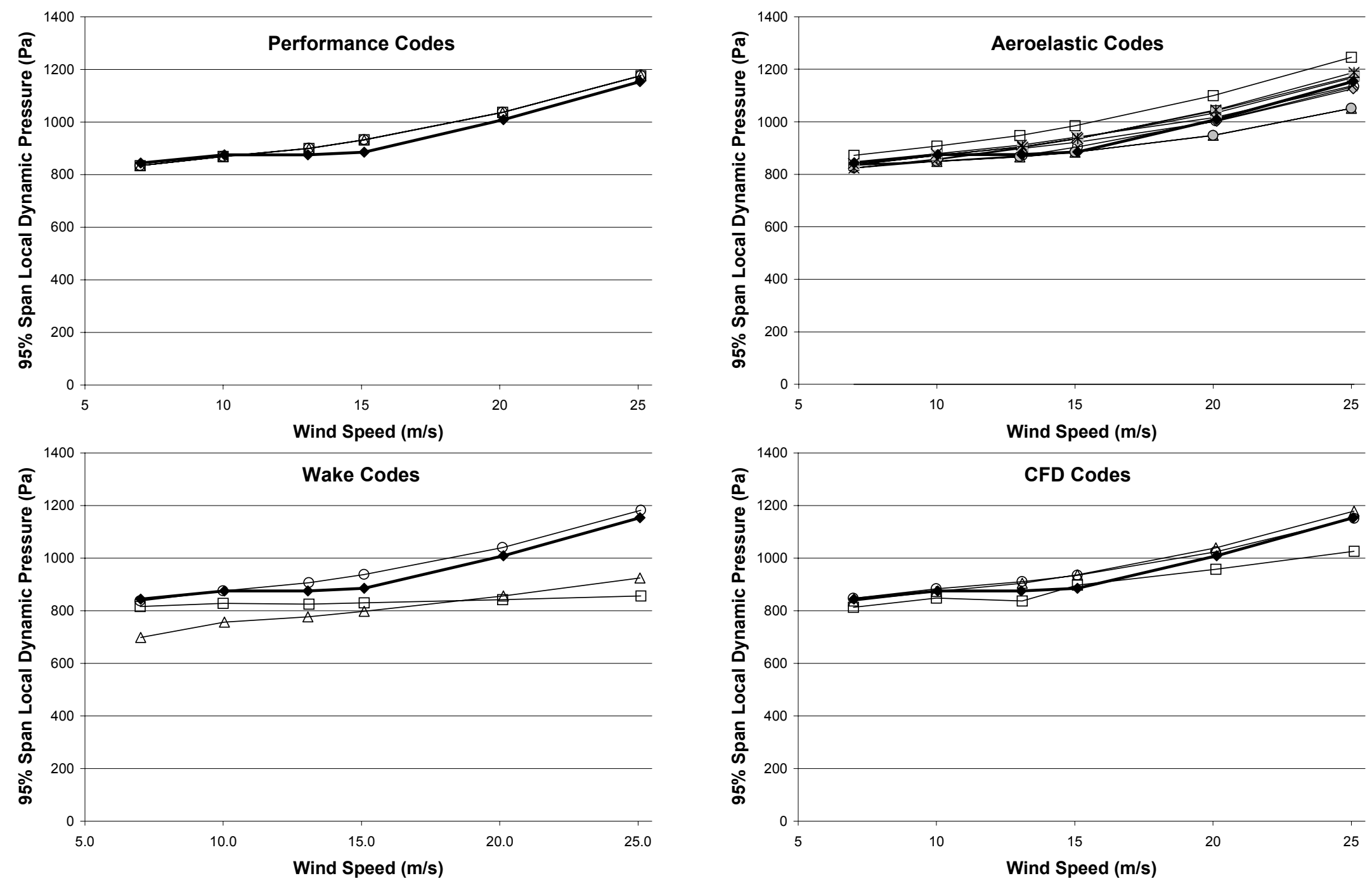

Figure 13. $0.95 \mathrm{R}$ local dynamic pressure, upwind, $0^{\circ}$ yaw 

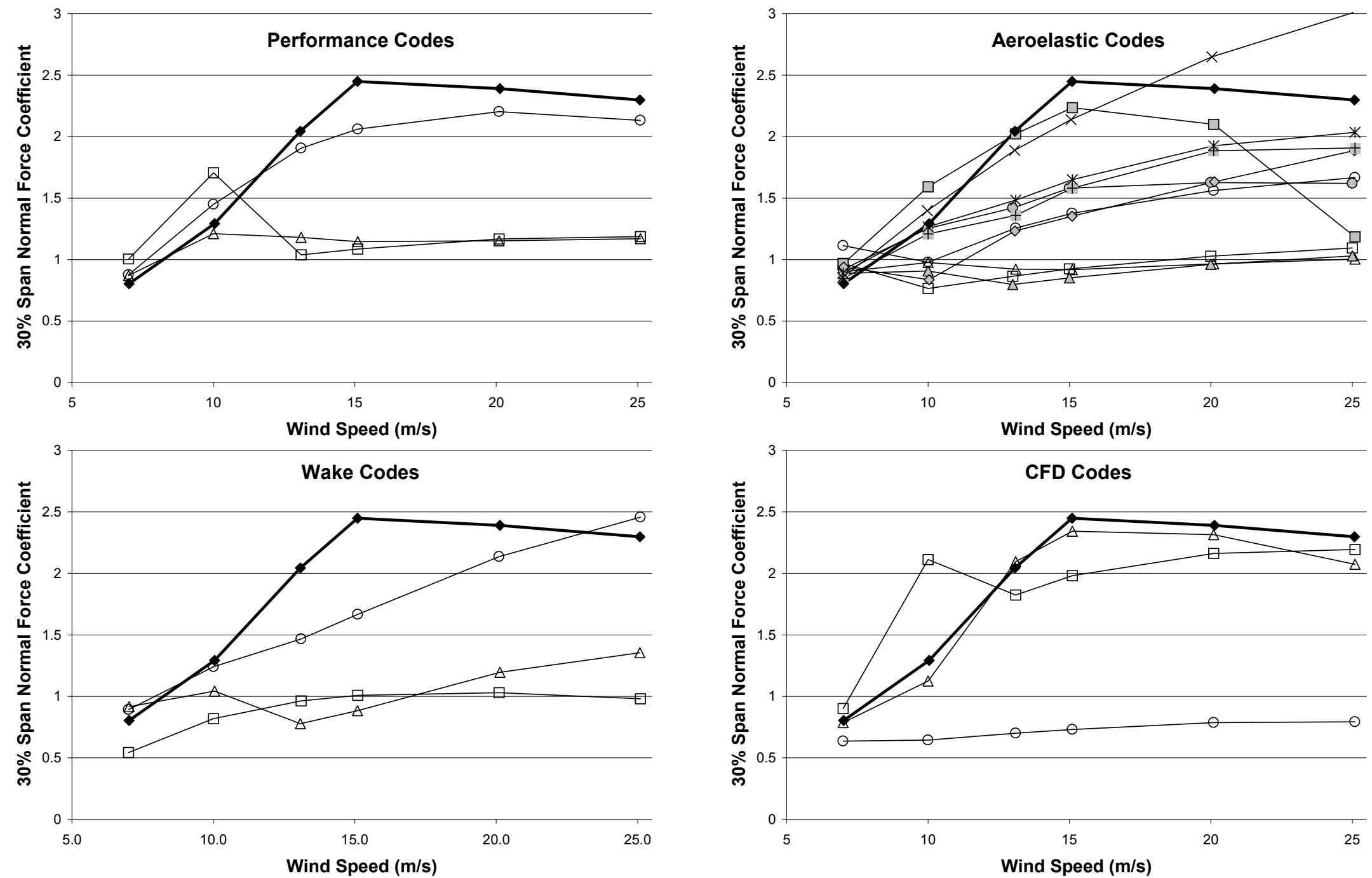

Figure 14. $0.30 \mathrm{R}$ normal force coefficient, upwind, $0^{\circ}$ yaw 

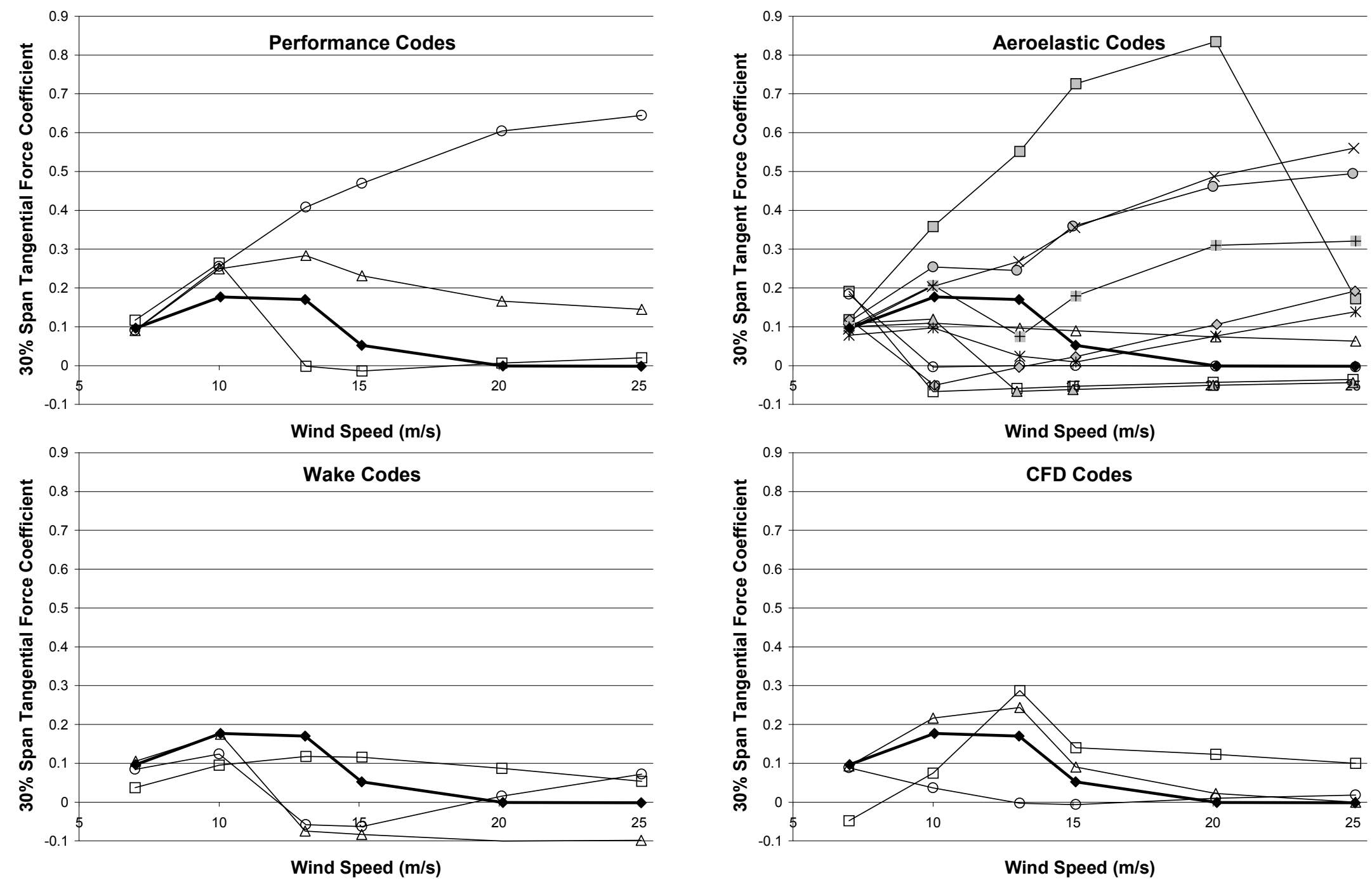

Figure 15. $0.30 \mathrm{R}$ tangent force coefficient, upwind, $0^{\circ}$ yaw 

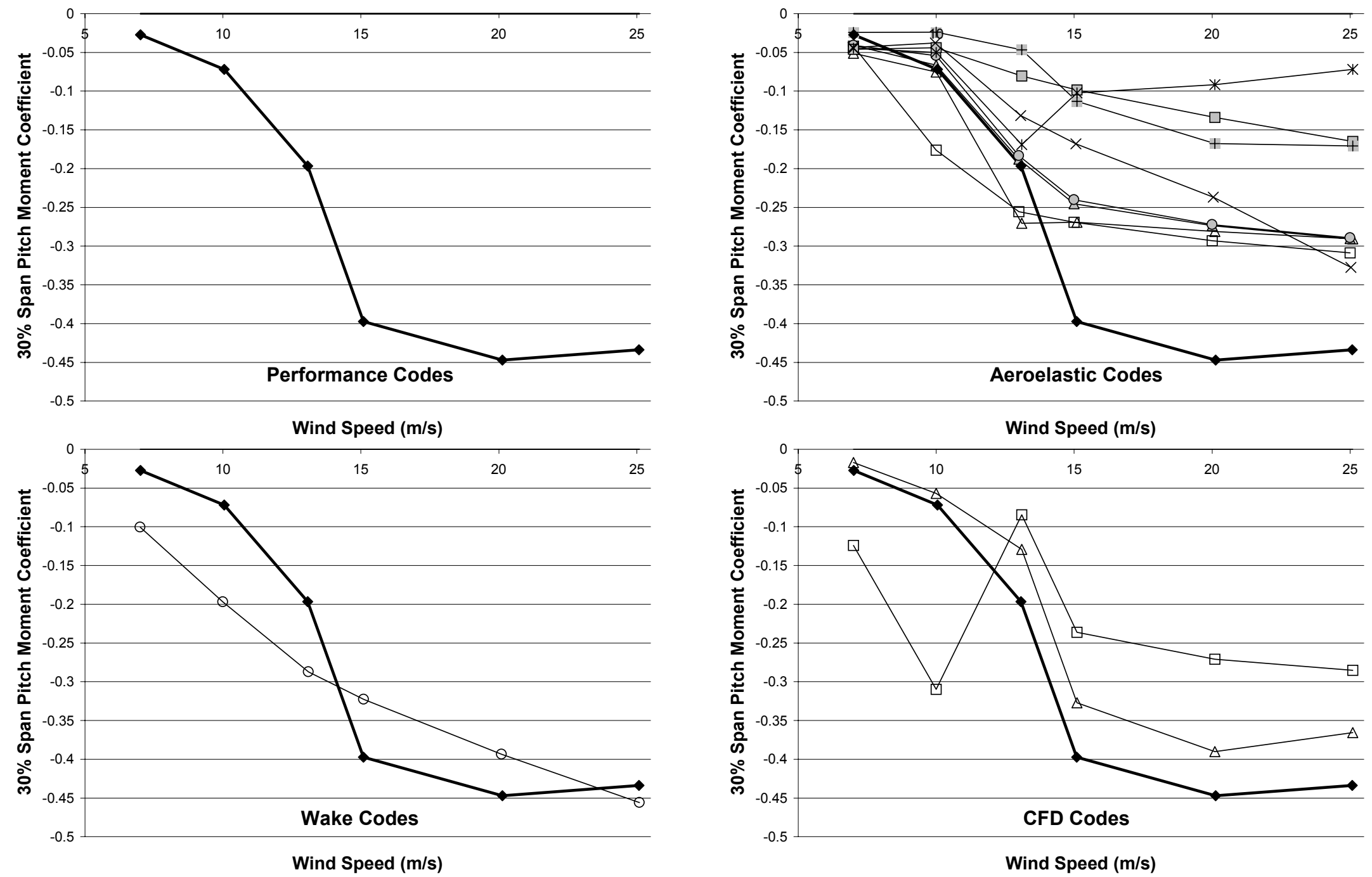

Figure 16. $0.30 \mathrm{R}$ pitch moment coefficient, upwind, $0^{\circ}$ yaw 

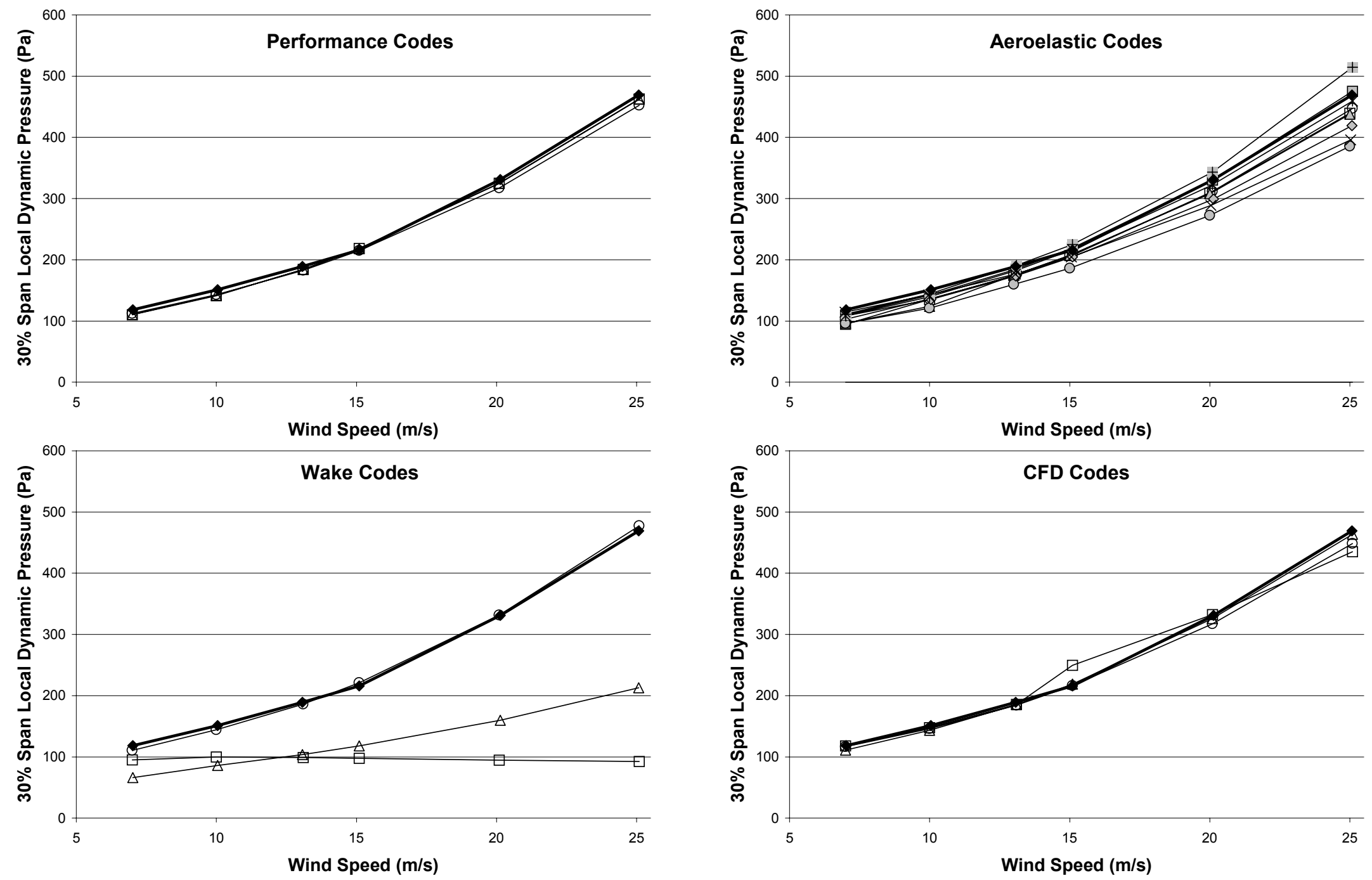

Figure 17. $0.30 \mathrm{R}$ local dynamic pressure, upwind, $0^{\circ}$ yaw 

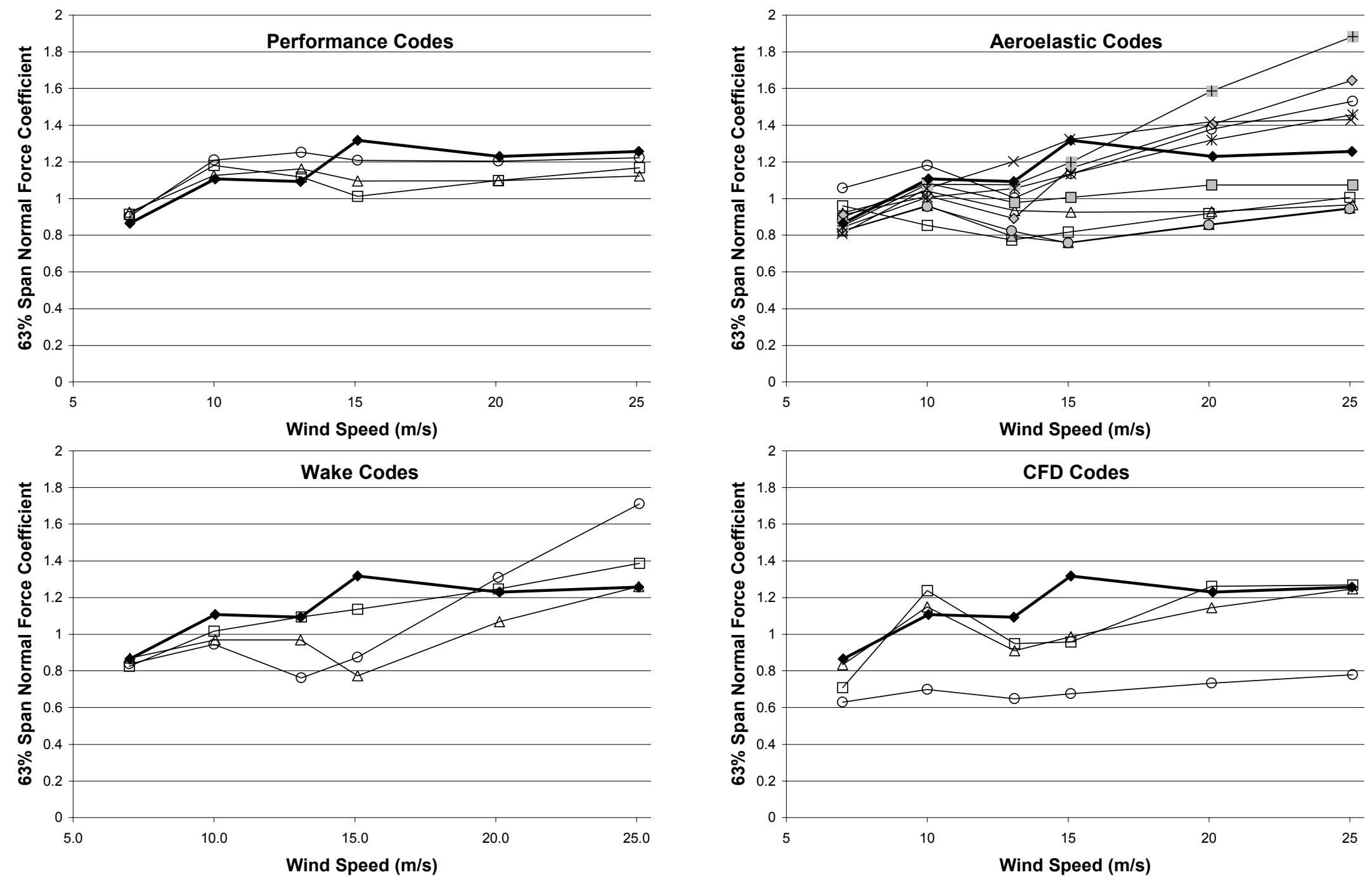

Figure 18. $0.63 \mathrm{R}$ normal force coefficient, upwind, $0^{\circ}$ yaw 

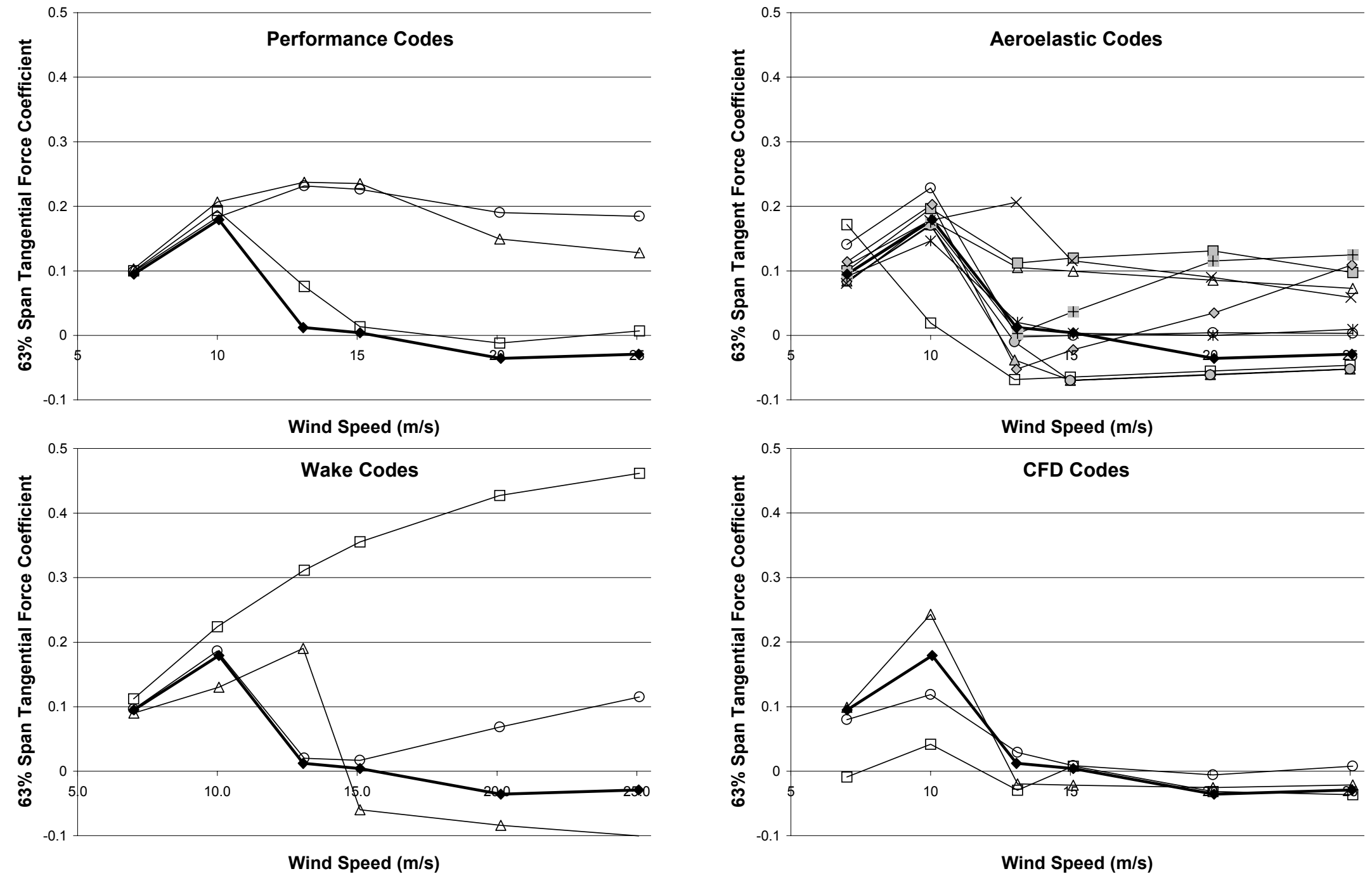

Figure 19. $0.63 R$ tangent force coefficient, upwind, $0^{\circ}$ yaw 

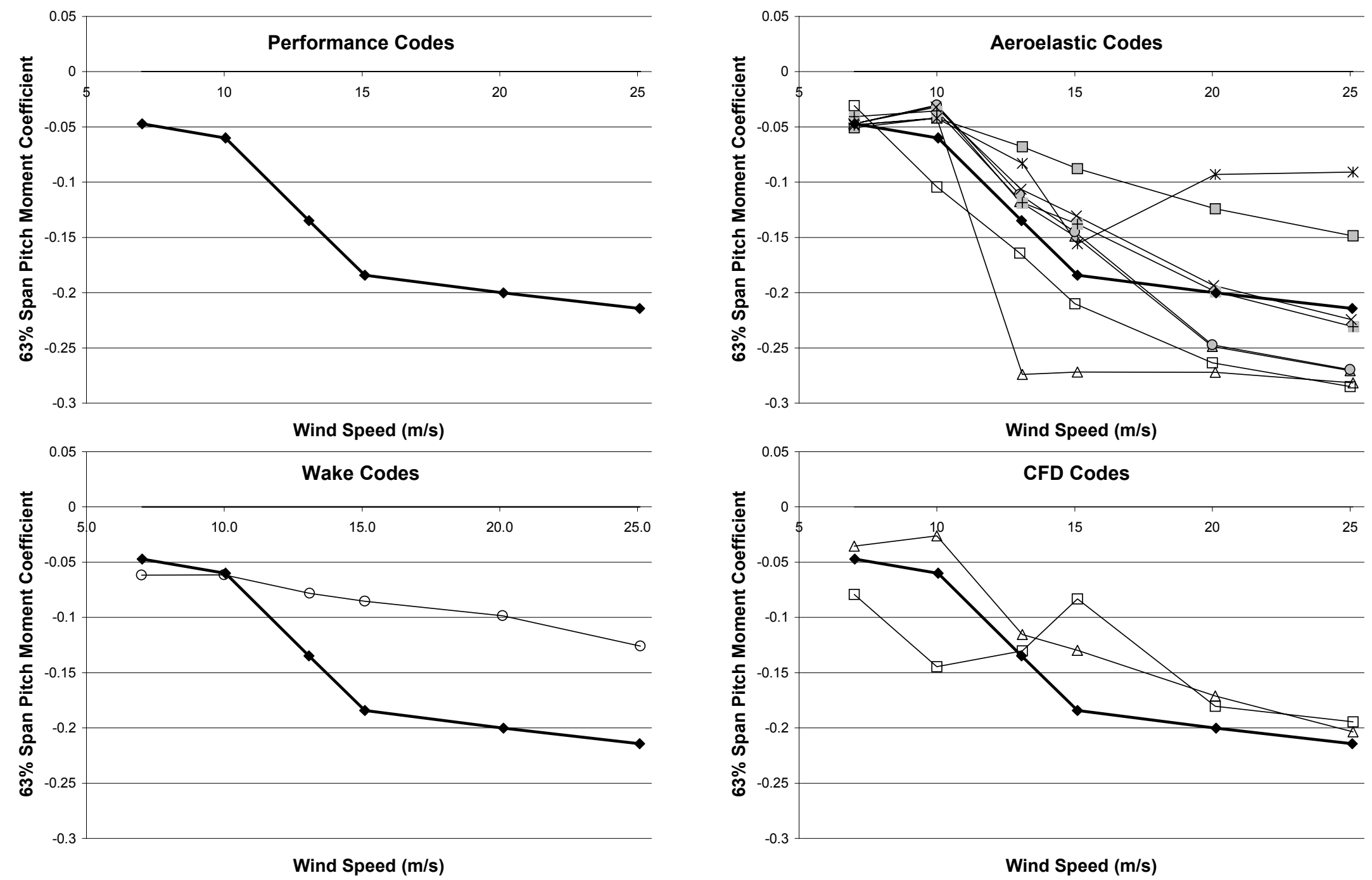

Figure 20. $0.63 R$ pitch moment force coefficient, upwind, $0^{\circ}$ yaw 

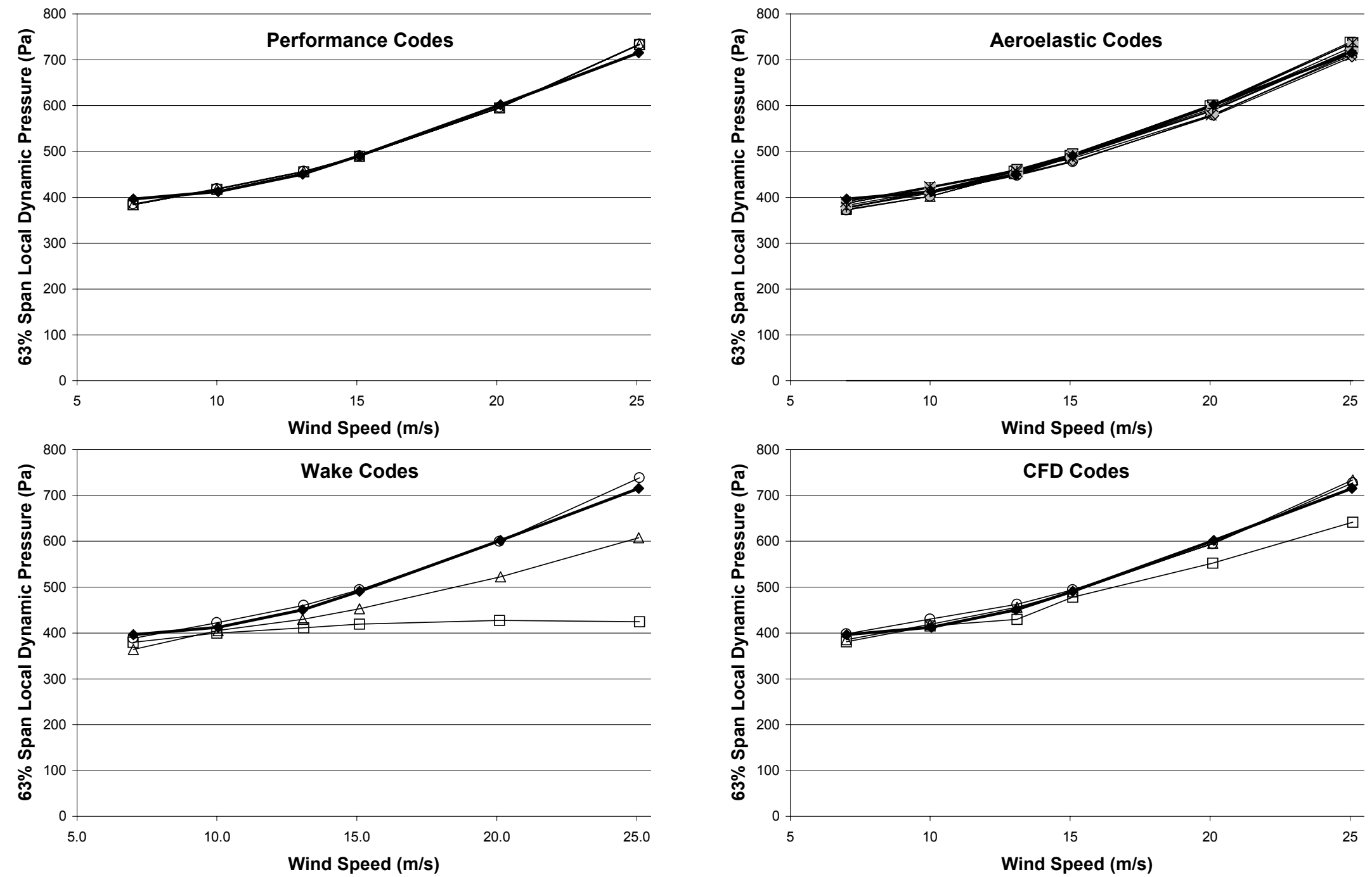

Figure 21. $0.63 R$ local dynamic pressure, upwind, $0^{\circ}$ yaw 

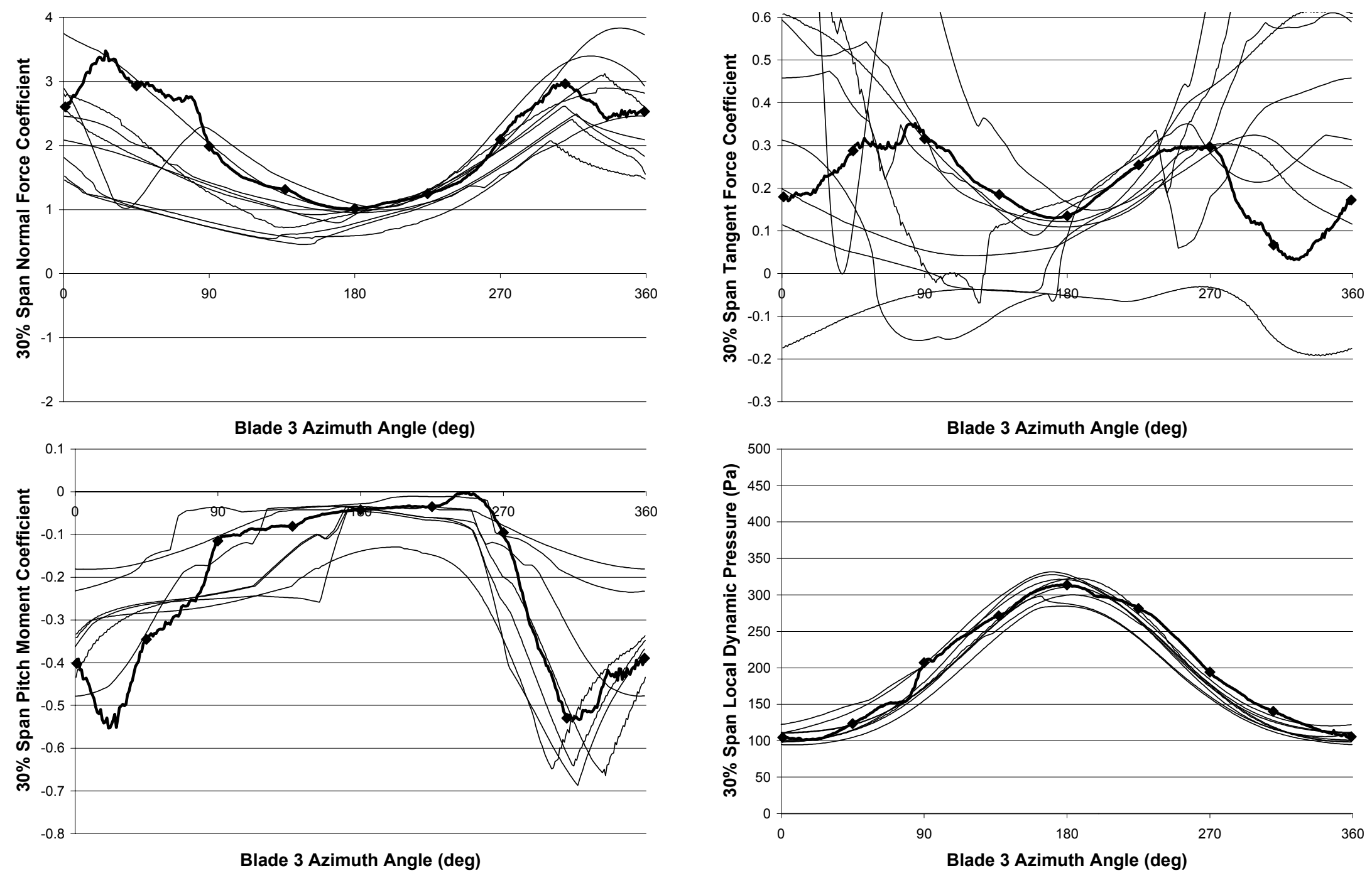

Figure 22. $0.30 \mathrm{R}, 15 \mathrm{~m} / \mathrm{s}$ wind speed, $30^{\circ} \mathrm{yaw}$, aeroelastic codes 

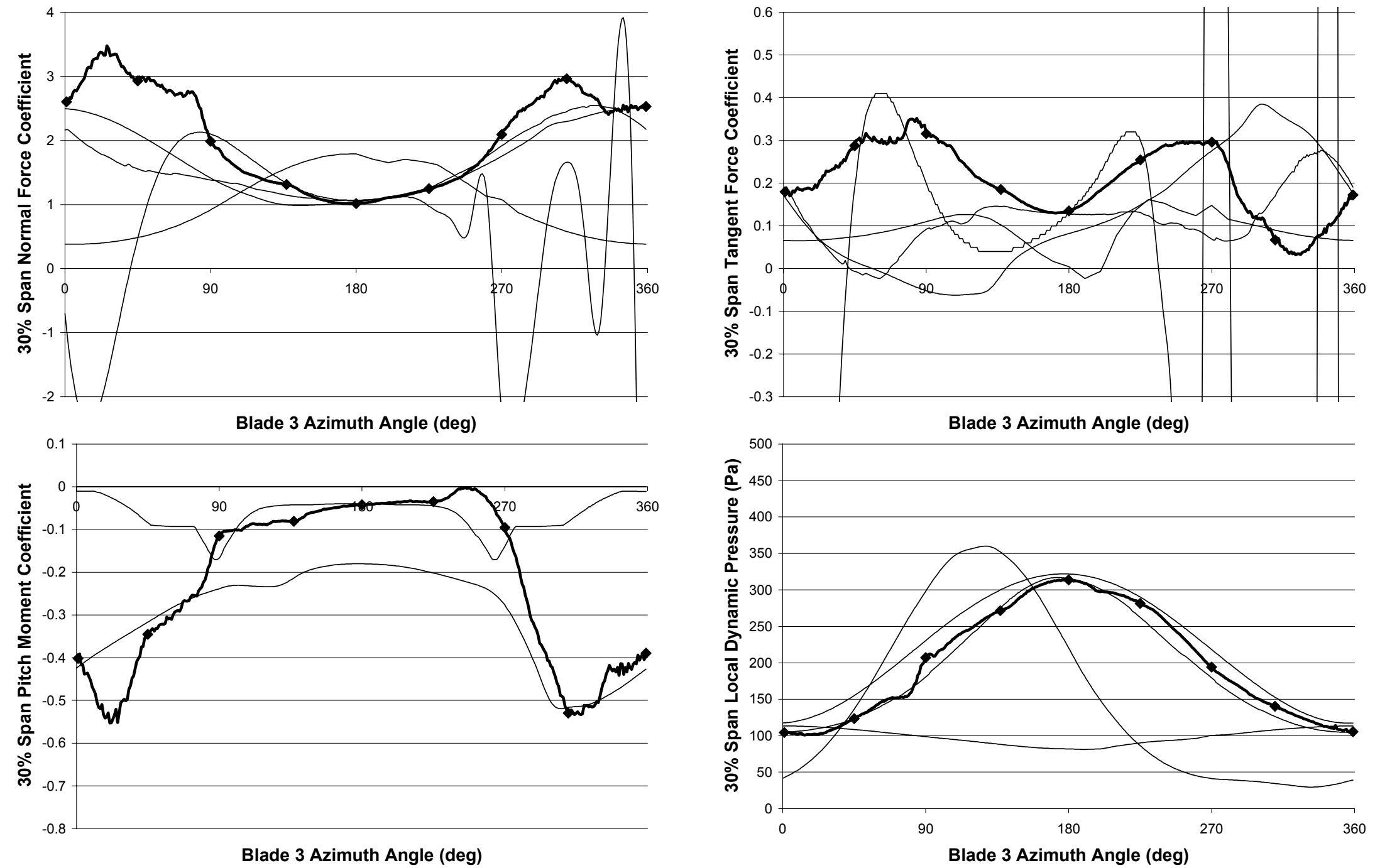

Figure 23 . $0.30 \mathrm{R}, 15 \mathrm{~m} / \mathrm{s}$ wind speed, $30^{\circ}$ yaw, wake codes 

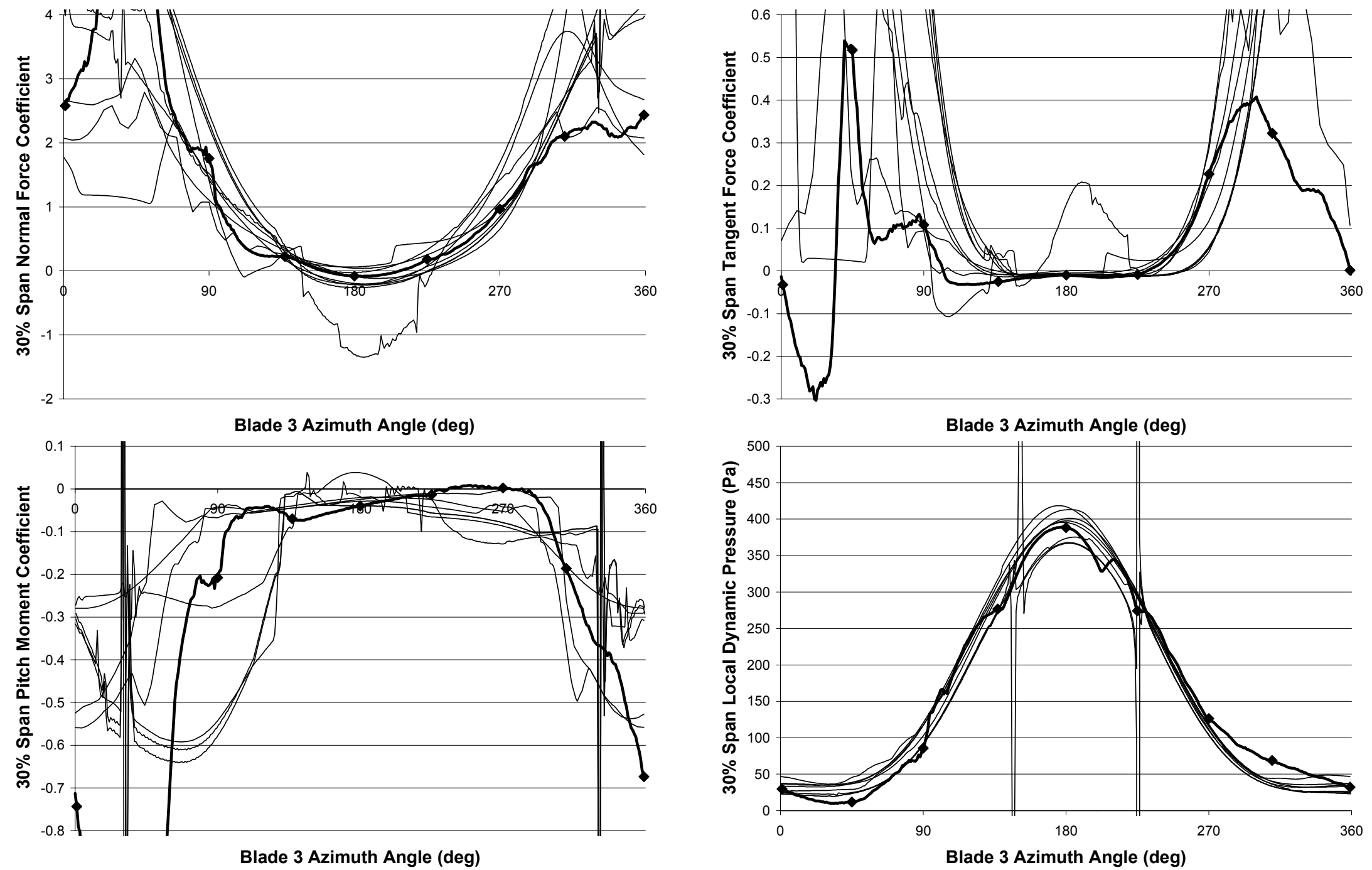

Figure 24. $0.30 \mathrm{R}, 15 \mathrm{~m} / \mathrm{s}$ wind speed, $60^{\circ}$ yaw, aeroelastic codes (Boom wake interference from $60^{\circ}-125^{\circ}$ azimuth) 

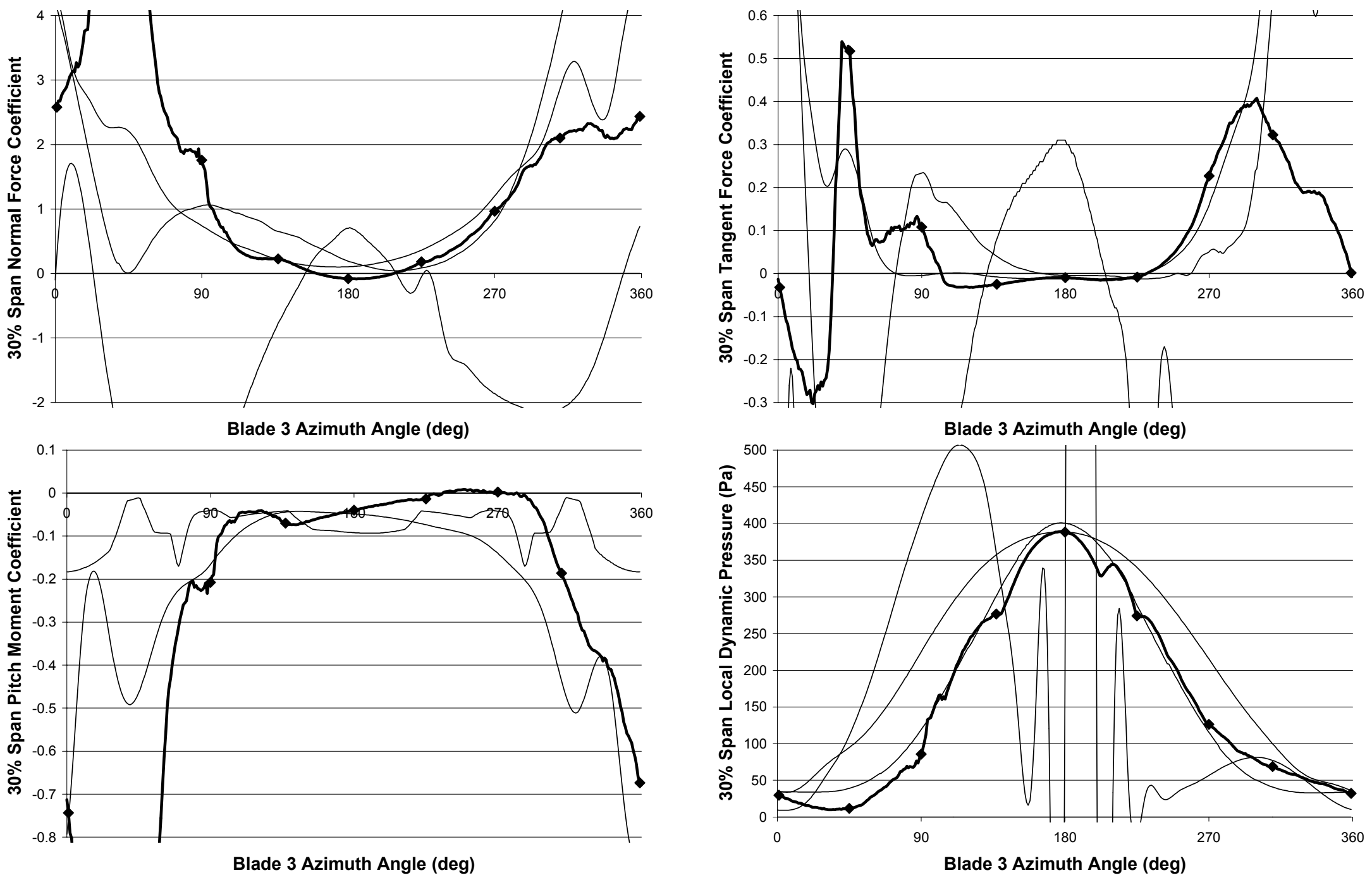

Figure 25. $0.30 \mathrm{R}, 15 \mathrm{~m} / \mathrm{s}$ wind speed, $60^{\circ}$ yaw, wake codes. (Boom wake interference from $60^{\circ}-125^{\circ}$ azimuth)

38 

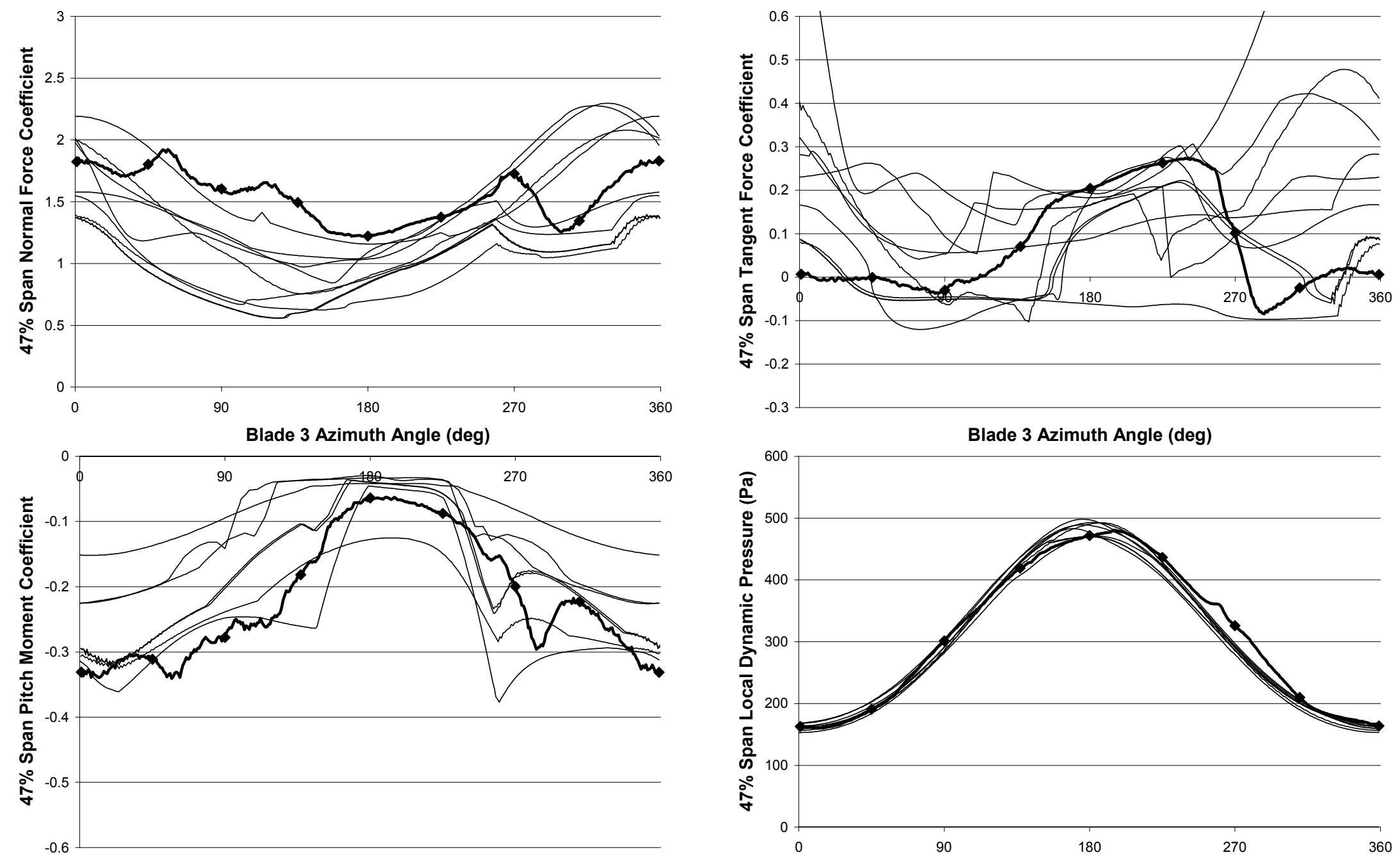

Blade 3 Azimuth Angle (deg)

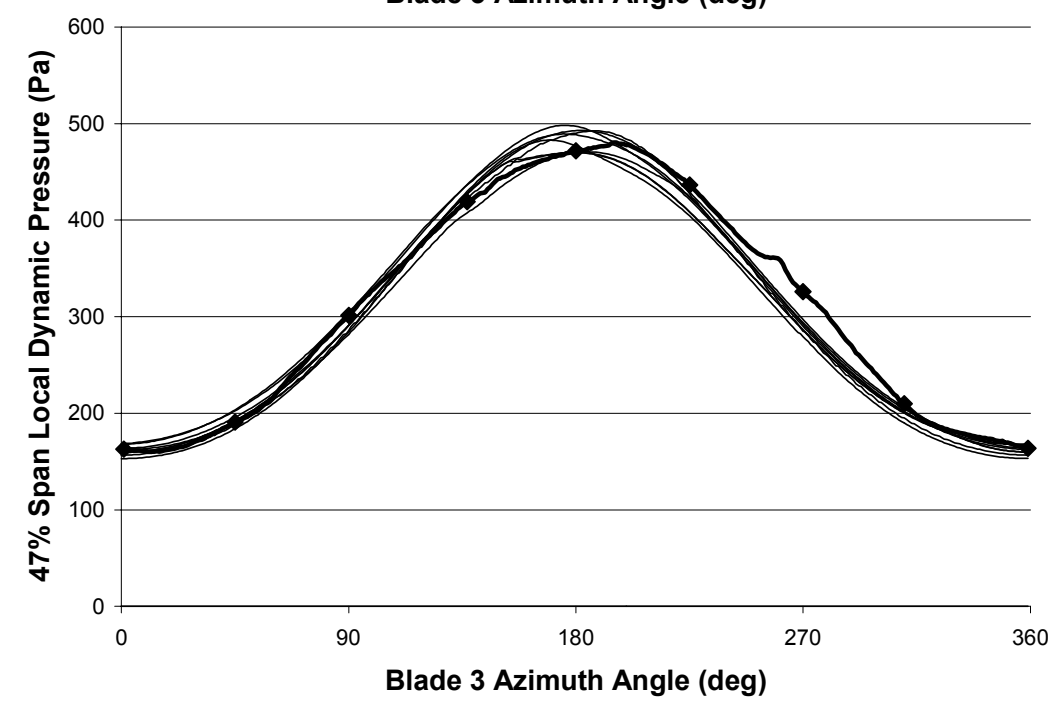

Figure 26. $0.47 \mathrm{R}, 15 \mathrm{~m} / \mathrm{s}$ wind speed, $30^{\circ}$ yaw, aeroelastic codes 

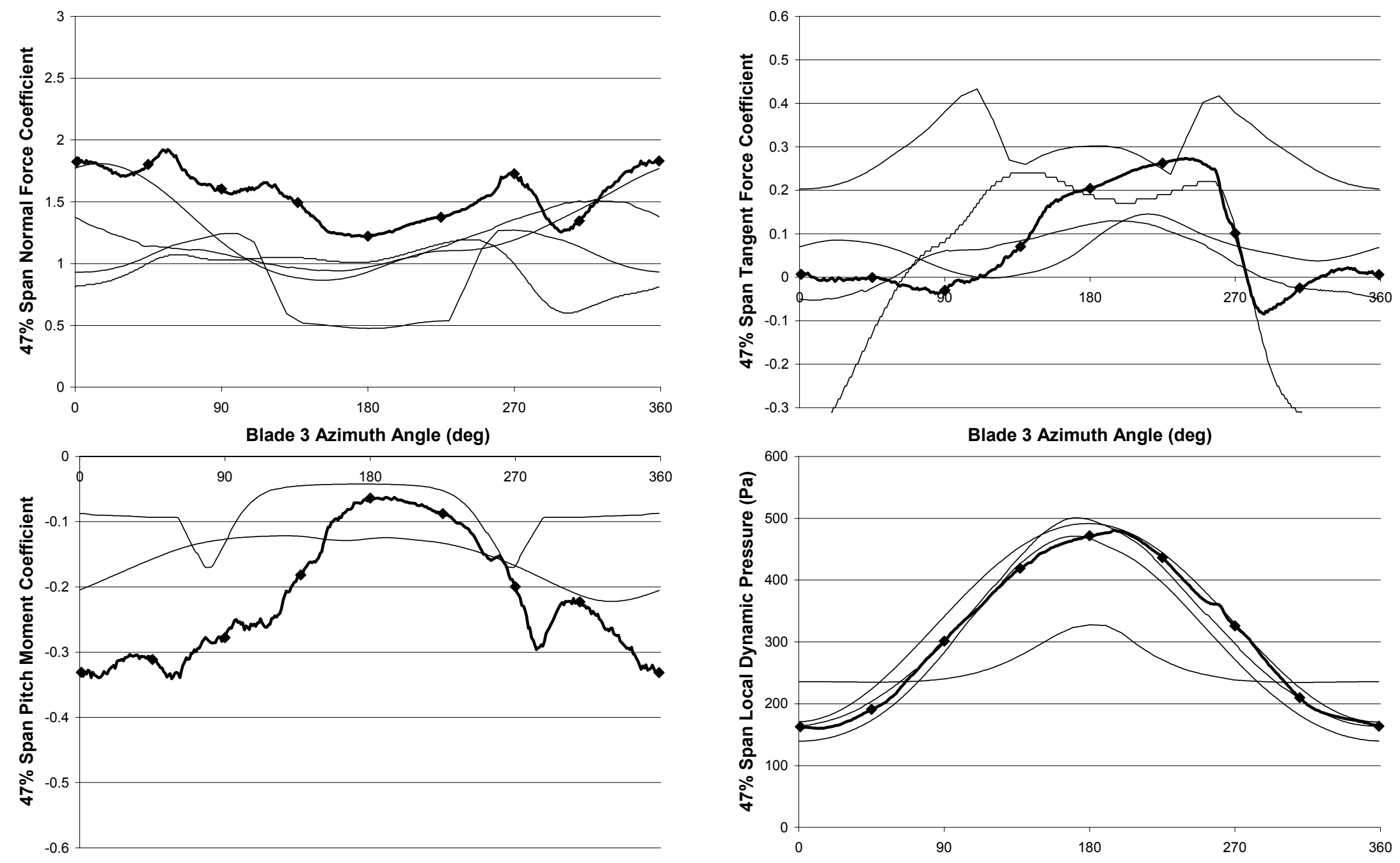

Blade 3 Azimuth Angle (deg)

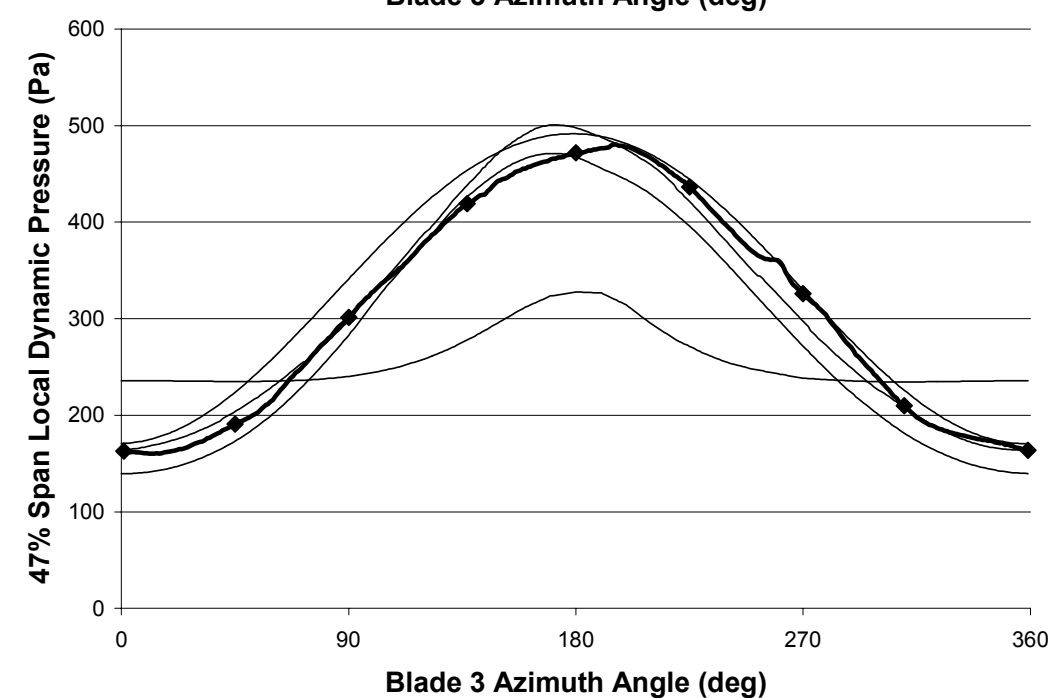

Figure 27. $0.47 \mathrm{R}, 15 \mathrm{~m} / \mathrm{s}$ wind speed, $30^{\circ}$ yaw, wake codes 

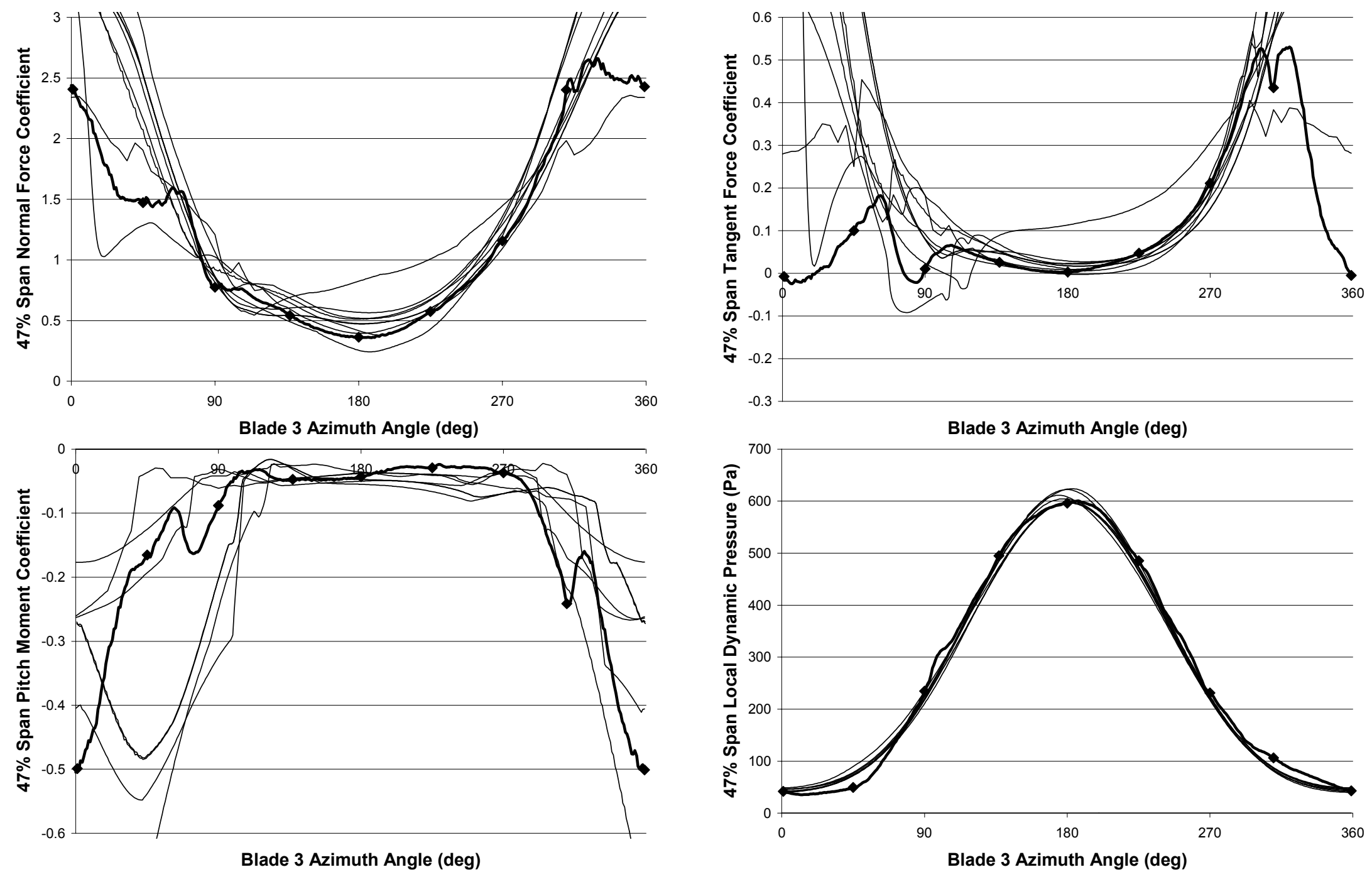

Figure 28. $0.47 \mathrm{R}, 15 \mathrm{~m} / \mathrm{s}$ wind speed, $60^{\circ}$ yaw, aeroelastic codes (Boom wake interference from $70^{\circ}-100^{\circ}$ azimuth) 

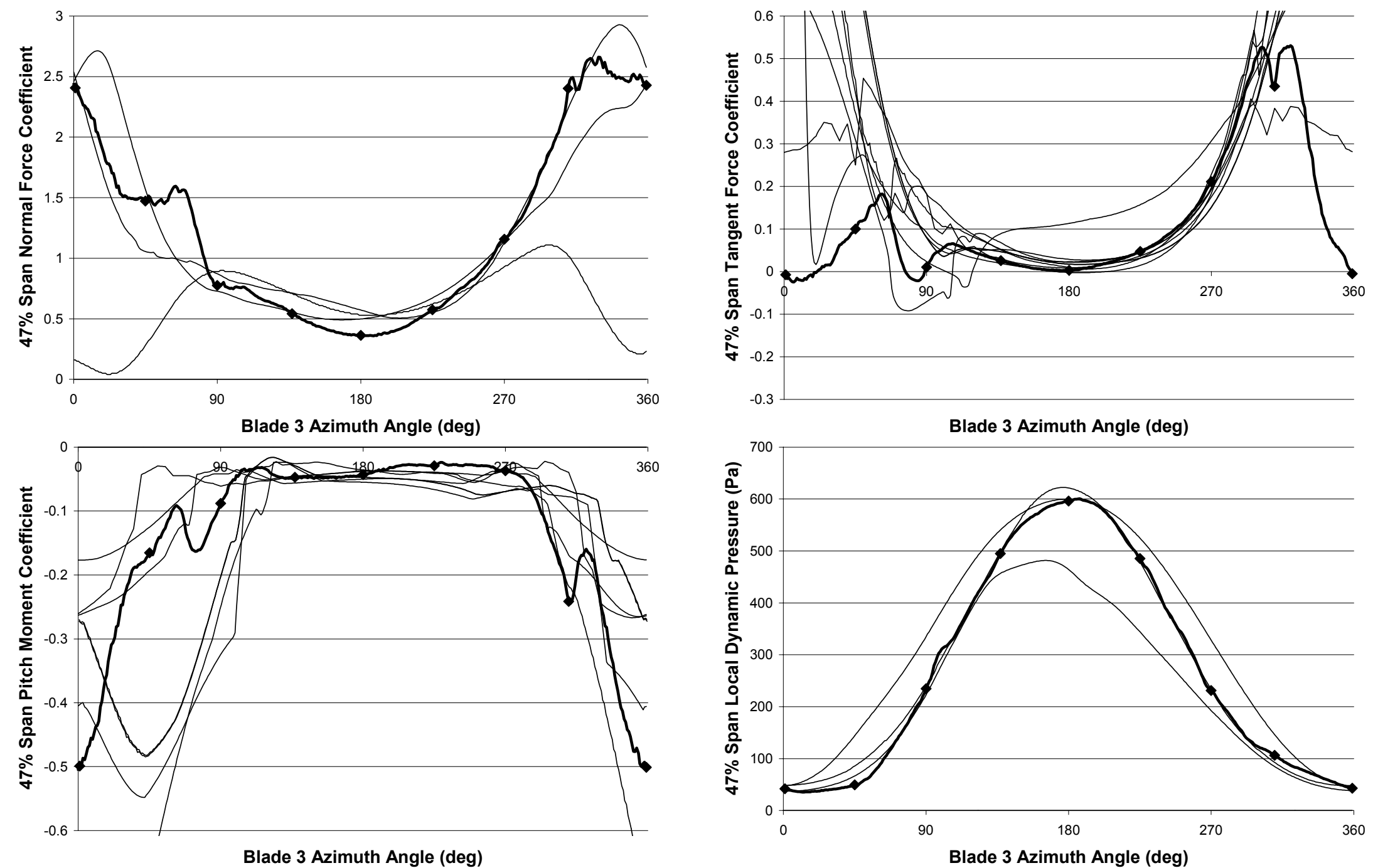

Figure 29. $0.47 \mathrm{R}, 15 \mathrm{~m} / \mathrm{s}$ wind speed, $60^{\circ}$ yaw, wake codes (Boom wake interference from $70^{\circ}-100^{\circ}$ azimuth) 

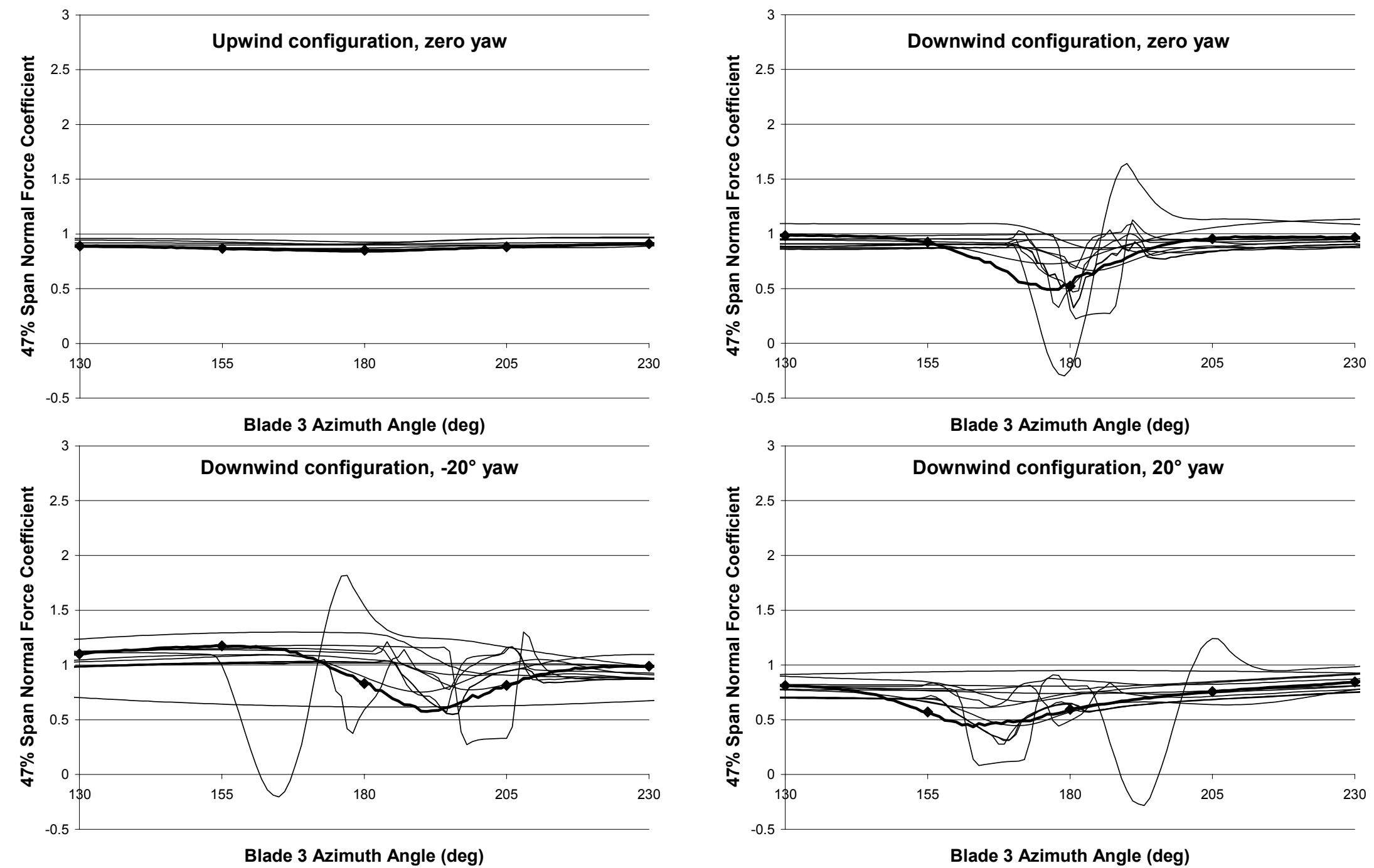

Figure 30. Tower shadow at $0.47 \mathrm{R}, 7 \mathrm{~m} / \mathrm{s}$ wind speed, aeroelastic and wake codes 

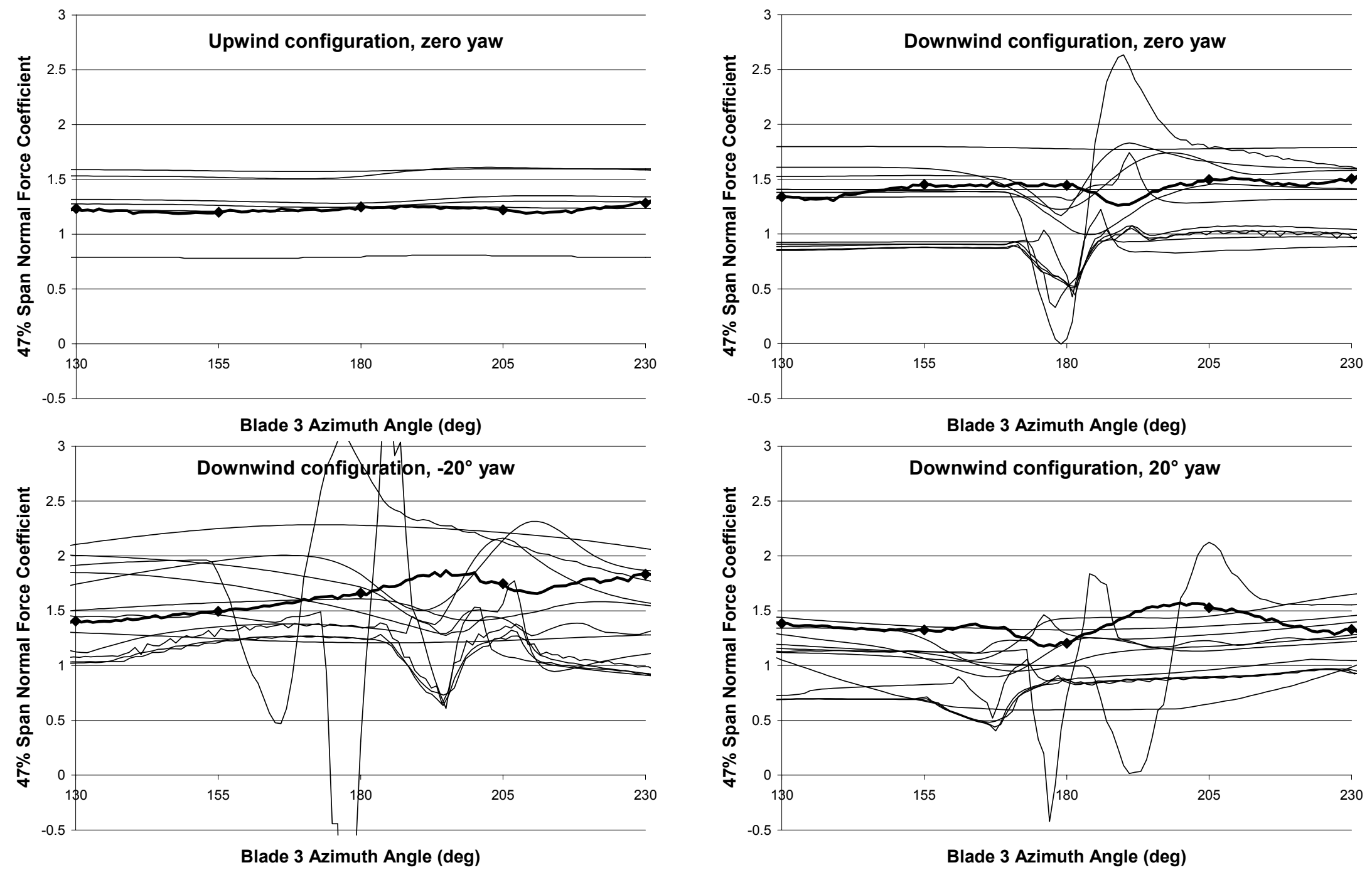

Figure 31. Tower shadow at $0.47 \mathrm{R}, 17 \mathrm{~m} / \mathrm{s}$ wind speed (upwind, zero yaw actually $15 \mathrm{~m} / \mathrm{s}$ ), aeroelastic and wake codes 


\section{REPORT DOCUMENTATION PAGE}

Public reporting burden for this collection of information is estimated to average 1 hour per response, including the time for reviewing instructions, searching existing data sources,

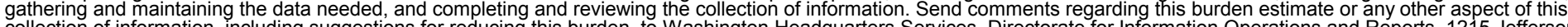
Davis Highway, Suite 1204, Arlington, VA 22202-4302, and to the Office of Management and Budget, Paperwork Reduction Project (0704-0188), Washington, DC 20503.
1. AGENCY USE ONLY (Leave blank)
2. REPORT DATE June 2001
3. REPORT TYPE AND DATES COVERED Technical Report

4. TITLE AND SUBTITLE

NREL Unsteady Aerodynamics Experiment in the NASA-Ames Wind Tunnel: A

Comparison of Predictions to Measurements
5. FUNDING NUMBERS

WER1.1110

6. $\operatorname{AUTHOR}(\mathrm{S})$

D. Simms, S. Schreck, M. Hand, L.J. Fingersh

7. PERFORMING ORGANIZATION NAME(S) AND ADDRESS(ES)

8. PERFORMING ORGANIZATION REPORT NUMBER

NREL/TP-500-29494

9. SPONSORING/MONITORING AGENCY NAME(S) AND ADDRESS(ES)

National Renewable Energy Laboratory

10. SPONSORING/MONITORING

1617 Cole Blvd.

Golden, CO 80401-3393

11. SUPPLEMENTARY NOTES

NREL Technical Monitor: NA

12a. DISTRIBUTION/AVAILABILITY STATEMENT

National Technical Information Service

12b. DISTRIBUTION CODE

U.S. Department of Commerce

5285 Port Royal Road

Springfield, VA 22161

13. ABSTRACT (Maximum 200 words)

Currently, wind turbine designers rely on safety factors to compensate for the effects of unknown loads acting on the turbine structure. This results in components that are overdesigned because precise load levels and load paths are unknown. To advance wind turbine technology, the forces acting on the turbine structure must be accurately characterized because these forces translate directly into loads imparted to the wind turbine structure and resulting power production. Once these forces are more accurately characterized, we will better understand load paths and can therefore optimize turbine structures.

To address this problem, the National Renewable Energy Laboratory (NREL) conducted the Unsteady Aerodynamics Experiment (UAE), which was a test of an extensively instrumented wind turbine in the giant NASA-Ames 24.4-m (80') by 36.6-m (120') wind tunnel. To maximize the benefits from testing, NREL formed a Science Panel of advisers comprised of wind turbine aerodynamics and modeling experts throughout the world. NREL used the Science Panel's guidance to specify the conditions and configurations under which the turbine was operated in the wind tunnel. The panel also helped define test priorities and objectives that would be effective for wind turbine modeling tool development and validation.

14. SUBJECT TERMS

Wind energy; wind tunnel testing; wind turbine aerodynamics; wind turbine structures; characterization; NASA-Ames; wind turbine modeling

15. NUMBER OF PAGES

16. PRICE CODE

17. SECURITY CLASSIFICATION OF REPORT Unclassified
18. SECURITY CLASSIFICATION OF THIS PAGE Unclassified
19. SECURITY CLASSIFICATION OF ABSTRACT Unclassified
20. LIMITATION OF ABSTRACT

UL 